\title{
Autoimmune Encephalitides
}

\section{David S. Younger}

Department of Neurology, New York University Langone Medical Center, New York University School of Medicine, The College of Global Public Health, New York University, New York, NY, USA

Email: david.younger@nyumc.org

How to cite this paper: Younger, D.S. (2017) Autoimmune Encephalitides. World Journal of Neuroscience, 7, 327-361. https://doi.org/10.4236/wjns.2017.73027

Received: July 24, 2017

Accepted: August 25, 2017

Published: August 28, 2017

Copyright (c) 2017 by author and Scientific Research Publishing Inc. This work is licensed under the Creative Commons Attribution International License (CC BY 4.0).

http://creativecommons.org/licenses/by/4.0/

\begin{abstract}
Autoimmune encephalitis is a potentially severe disorder of the brain of diverse causes with a complex differential diagnosis. Recent advances in the past decade have led to the elucidation of new syndromes and biological markers transforming the approach to diagnosis and management of autoimmune encephalitis. Limbic encephalitis, the commonest form of autoimmune encephalitis, combines common presentations of cognitive, psychiatric, and epileptic disorders and has until recently been considered paraneoplastic or postinfectious in origin. The autoimmune encephalitides are clinically and histopathologically associated with serum and intrathecal antibodies to intracellular and surface neuronal antigens, and constituents of the limbic system neuropil. This has led to a reconsideration of a number of neuropsychiatric and neurocognitive disorders as having shared mechanisms of origin. This chapter reviews their historical background, clinical presentation, laboratory evaluation, histopathology, diagnosis and management.
\end{abstract}

\section{Keywords}

Autoimmune, Encephalitis, Hashimoto, Encephalopathy

\section{Historical Perspective}

Corsellis and colleagues [1] coined the term limbic encephalitis (LE) in 1968, noting a relation to bronchial cancer in three patients in the sixth to eighth decade of life, and showing close clinicopathologic similarity to cases described by Brierley and colleagues [2] six years earlier. All three cases had subacute temporal lobe seizures, neuropsychiatric, and memory disturbances for two years before death. Postmortem examination showed inflammatory lesions in limbic grey matter sections of the brain, especially in medial temporal lobe structures of the uncus and amygdala nuclei, and hippocampal, cingulum and dentate gyri. Case 2 had an undifferentiated non-metastatic lung carcinoma removed six months after onset of neurological symptoms, while two others had a clinically unsus- 
pected malignancy at autopsy. Case 1 had a bronchial carcinoma restricted to a mediastinal lymph node without a primary lesion, while Case 3 had unsuspected oat cell carcinoma infiltrating the main bronchi of both lungs and adjacent mediastinal nodes.

A decade earlier, Henson and coworkers [3] described a patient with subacute cerebellar degeneration and concomitant features of subacute motor neuronopathy prior to discovery of occult breast carcinoma. Postmortem examination showed spinal cord anterior horn cell loss accompanied by focal lymphocytic inflammation, crescentic anterolateral cord demyelination sparing pyramidal tracts, and Wallerian motor nerve degeneration in the legs. The target antigen, Ri or anti-neuronal nuclear antibody type 2 (ANNA-2), named for the patient in whom it was identified, became synonymous with paraneoplastic opsoclonus myoclonus ataxia (POMA) syndrome and breast cancer. Younger and coworkers [4] extended that association in recognizing its occurrence in a patient with subacute motor neuronopathy. That patient's antiserum and cerebrospinal fluid (CSF) recognized a $55 \mathrm{kD}$ antigen present in tumor nuclei and the nuclear neuronal antigen Nova1 [5] expressed in the developing subcortical brain and ventral spinal cord motor system of humans and rodents [6] [7], and to Nova2, expressed in rostral neocortex [8].

A second intracellular onconeural serum and CSF autoantibody termed Yo or Purkinje cell antibody type-1 (PCA-1) was recognized by Greenlee and Brashear [9] and later by Giometto and colleagues [10] as the cause of paraneoplastic cerebellar degeneration (PCD) demonstrating reactivity of to both ovarian carcinoma nuclei and cerebellar Purkinje cell neurons.

At the same time, the investigations of Posner and colleagues [11] [12] focused on small-cell lung cancer (SCLC) and series of patients with a spectrum of encephalitic disorders, ranging from pure limbic encephalopathy to a diffuse and lethal encephalomyelopathy, frequently accompanied by dorsal root ganglionopathy. These patients shared a common feature, harboring high-titer autoantibodies, termed $\mathrm{Hu}$ or anti-neuronal nuclear antibody type-1 (ANNA-1) [11] [12] [13] [14] against a family of neuron-specific RNA binding proteins, termed $\mathrm{HuB}, \mathrm{HuC}$, and $\mathrm{HuD}$ [15] [16]. In the same year, 1991, Szabo and colleagues [17] described the paraneoplastic encephalomyelitis (PEM) antigen, and Dalmau and colleagues [18] described the clinical findings of 71 patients with anti-Hu and SCLC-associated PEM/sensory neuronopathy (PEM/PSN).

According to Darnell [19] the reason that some patients presented with a similar autoantibody but different disease symptoms was unknown, but the accomplishments in SCLC-associated PEM etched out a model for the pathogenesis of paraneoplastic encephalitis [16] [20]. In that model, SCLC triggered the neurological disorder by immune-mediated action at a distance. The normal neuron-specific nature of expression of the $\mathrm{HuB}-\mathrm{D}$ proteins related to its ability to trigger an antitumor immune response to nascent lung cancer cells, which in some patients was then linked to immune recognition of neurons normally expressing the $\mathrm{Hu}$ proteins, leading to neurological symptoms. 
Other syndromes associated with paraneoplastic encephalitis were elucidated by Dalmau and colleagues [21] [22] in their descriptions of anti-MA1 and MA2 and testicular cancer; and the collapsin response mediator protein-5 (CRMP5/Cv2) in association with thymoma [23]. Each with an intracellular target antigen, the resultant histopathology of these antibodies generally consisted of infiltrative cytotoxic (CD8+) T-cell destruction of neurons, with variable IgG and complement deposits in the CNS and dorsal root ganglia (DRG) (in the anti-Hu cases), and fewer helper (CD4+) T-cells, and generally absent CD20+ B-cells. Bernal and coworkers [24] and Blumenthal and colleagues [25] illustrated the role of infiltrating CD8+ cells in cell death by showing their close apposition to neurons.

In 2000, Bien and colleagues [26] and Mori and coworkers [27] described several patients with non-paraneoplastic LE. The interface of strictly paraneoplastic and autoimmune mechanisms was subsequently highlighted in the characterization of patients with stiff-person syndrome (SPS) associated with antibodies to glutamic acid decarboxylase (GAD); and the clinical neurological syndromes associated with voltage-gated potassium channel (VGKC)-complex antibodies.

The formulation of the relation of GAD antibodies to SPS has been especially instructive in understanding how far the science of autoimmune neurologic disorder has advanced. In 1988, Solimena and colleagues [28] investigated the existence of non-paraneoplastic CNS autoimmunity in a patient with SPS, epilepsy and type-1 diabetes (T1D), and increased titers of oligoclonal CSF IgG. Both the serum and CSF produced identical intense staining of all gray-matter regions. GAD65 was thence an important autoantigen in T1D, being highly expressed in the cytoplasm of pancreatic $\beta$ cells. GAD-derived peptides were presentable by main histocompatibility complex (MHC) class I molecules and recognized by CD8+ cells on the surface of $\beta$ cells [29]. Activation of CD8+ GAD-specific $\mathrm{T}$-cells further differentiated into memory cells suggesting a pathogenic role in T1D [30]. However, only patients with very high titers of GAD were associated with LE [31], and they typically presented with recent-onset temporal lobe epilepsy (TLE) and intrathecal secretion, defining a form of non-paraneoplastic LE. Other patients within the SPS spectrum harbored antibodies against other proteins of the GABAergic synapse, including amphiphysin and gephyrin, which were found to associate with lymphoma, malignant cancer of the breast, colon, lung, and thymus [32].

Contemporaneously, the clinical phenotypes associated with autoantibodies to VGKC-complex ranged from peripheral nerve hyperexcitabiity (PNH), to Morvan's syndrome (MoS), and LE and autoimmune epilepsy [33] [34]. VGKC-complex antibodies were detected in a case of MoS [35] and subsequently described in 2 patients with LE [36]. Both patients with LE were negative for typical paraneoplastic antibodies and had near-complete recovery, including one with recurrent thymoma after plasma exchange, while the other patient recovered spontaneously without specific immunotherapy. The immunoprecipitation of VGKC-complexes linked a number of clinical syndromes that might otherwise have remained separate. 
By 2010, Graus and colleagues [37] classified neuronal antibodies associated with syndromes resulting from CNS neuronal dysfunction into two groups according to the location of the target antigen. One group of well-characterized autoantibodies that recognized intracellular neuronal antigens included $\mathrm{Ri}$, Yo, $\mathrm{Hu}, \mathrm{Ma}$, CRMP5/Cv2 and GAD. These so called onconeural antibodies were useful in the designation of a specific paraneoplastic neurological disorder [38] [39] [40]. Bien and colleagues [41] described qualitative and quantitative immunopathologic features of biopsy or postmortem brain tissue in 17 cases of autoimmune encephalitis (AE) associated with intracellular (IAg) ( $\mathrm{Hu}, \mathrm{Ma} 2, \mathrm{GAD})$ or surface antigens (SAg) (VGKC-C and $N$-methyl-D-aspartate [NMDA]). Their studies noted higher $\mathrm{CD} 8+/ \mathrm{CD} 3+$ ratio and more frequent appositions of granzyme-B-positive $(\mathrm{GrB})(+) \mathrm{CD} 8+$ cells to neurons, with associated cell loss in the IAg-onconeural group compared to those in the SAg group. The exceptions were GAD cases that had less intense inflammation and a relatively low CD8+/CD3+ ratio compared to IAg-onconeural cases. A role for T-cell-mediated neuronal cytotoxicity was found in encephalitis associated with antibodies directed against IAg, whereas a complement-mediated humoral immune mechanism was suggested in VDKC-complex encephalitis. There was apparent absence of both mechanisms in NMDA receptor encephalitis.

Bauer and Bien [42] suggested that neurodegeneration in brains of patients with antibodies against IAg was not simply induced by antibody reactivity with the target antigen, but rather by the inflammatory $\mathrm{T}$-cells. To be pathogenic, the imputed antibody first had to transit the blood-brain barrier (BBB), then the target cell neuronal membrane to a location where it could bind the pathogenic intracellular antigen. Depending upon protein conformation and folding, the antigenic site might be readily accessible before inactivation and ensuing irreparable cell damage. It is difficult to imagine that an intracellular antibody could easily overcome each of these obstacles. Although there have not been in vivo studies revealing neuronal cell death due to infiltration with onconeural antibodies against putative IAg, in vitro studies have shown somewhat contradictory results, with earlier studies demonstrating accessed cultured neurons without damage [43] and later ones demonstrating induction of cell death after antibody uptake [44]. A major concern in managing these disorders has not only been prompt treatment of the tumor, but commencement of effective immunotherapy targeting mainly cytotoxic T-cells [45]. Vasculitis has not been a recognized mechanism of injury in intraneuronal antibodies, either in life or at postmortem examination.

The past decade witnessed the emergency of serum autoantibodies against SAg and synaptic-enriched regions leading to LE that spared the cytoplasm and nuclei of neurons, such as those against GluN1 or GluN2/3 synaptic subunits of $N$-methyl-D-aspartate (NMDA) [46] and glycine receptors [47]; and the $\alpha$-amino-3-hydroxy-5-methyl-4-isoxazolepropionic acid (AMPA) receptor [48]. Several novel neuropil antigens that localized to neuronal and dendritic cell surface co-localized with synaptophysin and spinophilin [49]. 
Supportive of LE or AE, these new antibodies shared the property of strong immunolabeling of areas of dense dendritic network and synaptic-enriched regions in the neuropil of hippocampus, sparing most neuronal cell bodies. The clinical phenotype associated with the novel neuropil antibodies included dominant behavioral and psychiatric symptoms and seizures. With inconstant features of cognition and memory, brain-magnetic resonance imaging (MRI) and 2-deoxy-2-[fluorine-18] fluoro-D-glucose $\left({ }^{18} \mathrm{~F}\right.$-FDG PET) abnormalities were less frequently restricted to the medial temporal lobe than in patients with classical paraneoplastic and VGKC-complex antibodies.

A role for the autoimmune dysfunction in neuropsychiatric illness has been sought since the 1930s when autoantibodies were first reported in a schizophrenia patient [50]. Since that time, there have been reports of specific autoimmune responses to self-antigens in psychosis, affective disorders, and other neurobehavioral abnormalities [51] [52]. Clinical neurologists, neuroscientists and psychiatrists, all have a stake in the emerging link between autoimmunity and resulting neurologic and psychiatric disorders in $\mathrm{AE}$ [53].

\section{Autoimmune Encephalitides}

One autoantibody associated with LE targets an IAg (GAD65), while three others target a neuronal SAg (NMDA receptor, VGKC-complex, and AMPA receptor) (Table 1). Classically, symptoms associated with them evolve over days to weeks and include neurocognitive and neurobehavioral manifestations as diverse as short-term memory loss, sleep disturbances, TLE, irritability, depression, hallucinations, and personality change, implicating inflammatory involvement of the limbic system, which includes the medial temporal lobes, frontobasal and cingular regions.

\subsection{Anti-GAD65 Encephalitis}

Background: Autoimmunity targeting the 65 kilo Dalton $(\mathrm{kDa})$ isoform of GAD65 encompass diverse autoimmune disorders such as T1D and rare neurologic disorders including LE, temporal lobe epilepsy (TLE), cerebellar ataxia, and large and small fiber peripheral and autonomic neuropathy [54].

Table 1. Non-paraneoplastic antibody-associated encephalitides.

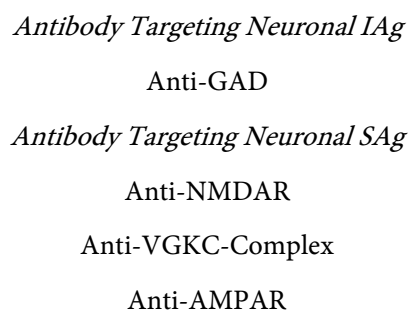

Abbreviations: IAg: intracellular antigen; SAg: surface antigen; GAD: glutamic acid decarboxylase; NMDA: $N$-methyl-D-aspartate; VGKC: voltage-gated potassium channel; AMPA: $\alpha$-amino-3-hydroxy-5-methyl4-isoxazolepropionic acid; R: receptor. 
Epidemiology: A review of adult-onset SPS showed a prevalence estimate of 1 in 1,250,000 [55] with a predominance of women, and average age of onset of 40 years [56]. The frequency of high titers of anti-GAD antibodies defined an RIA value $>1000 \mathrm{IU} / \mathrm{ml}$ in TLE of unknown origin is $21 \%$ of cases, with the highest titers related to TLE [57]. Affected patients were typically women with T1D, early-onset TLE, and concomitant hypothyroidism, psoriatic arthritis and Celiac disease, a third of whom reported onset of LE as the predominant feature, with supportive findings of amygdala and hippocampus signal intensities on brain MRI, and medial temporal hypometabolism on FDG brain PET. The levels of anti-GAD ranged from 1207 to $87,510 \mathrm{IU} / \mathrm{ml}$, with absent $\mathrm{OCB}$, and a ratio of serum/CSF anti-GAD antibody levels $>1$ suggesting intrathecal synthesis. Malter and colleagues [58] estimated the prevalence of anti-GAD antibodies in LE to be $17 \%$, noting a subgroup of patients with TLE who had very high titers equivalent to those with SPS, medial temporal inflammation on MRI, and concomitant LE. In the TLE cohort, GAD antibody encephalitis proved to be equally common to VGKC-complex antibodies but differed in younger age, female sex, and presentation of first seizure, CSF oligoclonal bands, and intrathecal autoantibody synthesis.

A recent retrospective analysis [58] of patients with paraneoplastic neurologic syndromes from 1995 to 2013 defined by the criteria of Graus and colleagues [59] detected high GAD antibody levels (>2000 U/mL) by RIA in 15 patients. Six patients (40\%) presented with encephalitis (5 typical LE); 6 PCA, 2 SPS, 1 POMA, 1 PEM, and 1 with a syndrome of vertigo, ataxia, axial rigidity and dysautonomia. Six patients had lung cancer (4 SCLC), 4 neuroendocrine tumors (2 pancreas and 2 thymic carcinoids), 2 thymoma, 2 breast cancer, and 1 patient had non-Hodgkin lymphoma. Cancer preceded the neurological diagnosis by a median delay of 3 months. In 3 tumors so studied ( 2 pancreatic and 1 thymic carcinoma), all expressed GAD65 antigenicity. In a comparison to 106 patients with non-paraneoplastic neurological syndromes, the latter group had encephalitis in 16\% (none LE); with nearly equal prevalence of PCD and SPS (67\%), and $18 \%$ isolated epilepsy.

Clinical Aspects: Gangnon and Savard [60] reviewed the clinical experience of 58 cases of GAD65-antibody LE beginning with the first reported case [61] inclusively through 2016, in 7 observational studies, 3 case series, and 21 published case reports [31] [49] [62]-[88]. They provide a useful summary of the literature of anti-GAD65 associated LE. Among the 58 cases, there were 21 children and 37 adults, $59 \%$ of whom were female, with a median pediatric age of 10 years (range 1 - 17 years) and mean adult age of 39 years (range 19 - 70 years). Diabetes alone, generally T1D, was noted in $50 \%$ of cases, in association with thyroiditis, diabetes, Celiac disease, psoriasis, and common variable immune deficiency respectively in $73 \%, 18 \%, 9 \%$, and $9 \%$. Cancer was noted in $6(10 \%)$ cases, including 4 SCLC and 2 malignant thymomas, generally in men of mean age 61 years (range 38 - 70 years).

The commonest presenting clinical features were seizures in 56 (97\%) cases, 
most commonly refractory status epilepticus; cognitive impairment in 38 (59\%) mainly affecting memory, language, executive function, and attention; and psychiatric symptoms in 16 (28\%) cases, most commonly depression, behavior, perception, and anxiety. Less common clinical manifestations included fever, dysautonomia, cerebellar incoordination and headache respectively in 8 (12\%), 7 (12\%), 4 (7\%), and $3(5 \%)$ cases. The most common seizure presentation was refractory status epilepticus. Mild muscular rigidity [62] and SPS [71] were diagnosed in 2 cases, as well as myoclonus [68] [73] [74] and facial cramps [62] in 4 others.

Cellular and Synaptic Antibody Effects: The structural biology of GAD autoantigen has been previously reviewed [89]. Low titers of anti-GAD65 antibodies, generally $<20 \mathrm{nmol} / \mathrm{L}$ occur in T1D and in the general population, while cases of anti-GAD65-associated neurological disorders including LE are seen in the hundreds of $\mathrm{nmol} / \mathrm{L}$. Two GAD isoforms with distinct localizations and functions, GAD65 and GAD67, are expressed in presynaptic CNS GABAergic neurons, and in pancreatic $\beta$ cells. Glutamic acid decarboxylase converts L-glutamate to GABA using pridoxal-5'-phosphate (PLP) as a cofactor. GABA is the commonest inhibitory neurotransmitter in the CNS and the ligand for the inhibitory voltage-gated chloride channel $\mathrm{GABA}_{\mathrm{A}}$, and G-protein coupled $\mathrm{GABA}_{\mathrm{B}}$ receptors. GAD67 commonly coexists with GAD65 antibodies in patients with neurologic autoimmunity. However GAD67 is rarely an autoantigen in isolation, found predominantly in the cytoplasm where it produces basal levels of GABA; whereas GAD65 is located predominantly in nerve terminals anchored to the cytoplasm-facing side of synaptic vesicles where it believed to synthesize GABA for neurotransmission supplementary to basal levels. The classification of high titers of anti-GAD65 autoantibodies has been problematic in being grouped with onconeural autoantibodies directed at an IAg [41] since they are not consistently paraneoplastic in origin.

Laboratory Investigations: A dominant clinical phenotype of seizures, neurocognitive and neuropsychiatric disturbances in most patients with anti-GAD-autoantibody associated LE has been explained by the frequent involvement of the medial temporal lobes; an inflammatory CSF with intrathecal secretion of the anti-GAD65 autoantibody, and oligoclonal bands. Bien and colleagues [90] described a 24-year-old woman with TLE, non-paraneoplastic LE, and a serum anti-GAD65 antibody titer of 1:32,000, in whom $\mathrm{T}_{2} /$ FLAIR MRI evolved over a period of 8 months, demonstrating right hippocampal swelling and signal increase to sclerosis and atrophy on MRI commensurate with clinical progression. The same authors [41] extended their findings to two other patients age 18 and 31 years, with a respective duration of disease of 127 and 115 months, manifesting refractory TLE and LE. The latter patient showed similar evolution of medial temporal atrophy in the context of $\mathrm{T}_{2} /$ FLAIR hyperintensities during the disease course. The remaining patient who had unilateral encephalitic $\mathrm{T}_{2}$-hypersignal in the left amygdala was found at the time of epilepsy surgery to have a normal MRI without medial temporal brain atrophy despite a 10-year 
disease history.

Among 58 literature patients [60], 45/58 (78\%) patient MRIs were abnormal with specific involvement of the temporal lobes in 34 (59\%), and multifocal abnormalities in 9 (16\%); and 7 patient MRIs were normal.

The results of electroencephalography (EEG) available in 35 cases, showed epileptiform discharges in 27 (77\%), and focal temporal involvement in 19 (70\%). Lumbar CSF so studied in 41 cases, showed pleocytosis in 11 (27\%) with white blood cell (WBC) counts ranging from 7 to 114 cells/uL; and present oligoclonal bands in one-half of cases. Hyponatremia was identified in 3 cases. There were significantly elevated titers of anti-GAD65 antibodies in both serum and CSF in 35 patients; and in either serum (in 18) or CSF alone in 3. Concurrent antibodies were reported in 11 cases, including those to $\mathrm{GABA}_{\mathrm{A}}$ in 5 cases, and VGKC-complex or $\mathrm{GABA}_{B}$ in 3 cases. Antibodies to NMDA receptor and AMPAR, and onconeural antibodies were all absent.

FDG brain PET imaging and MRI were complementary in 50\% of cases [49]. Combining both MRI and PET, all patients had temporal lobe abnormalities. EEG may be useful in classifying the seizure type and directing the use of anticonvulsants especially when clinical seizures lack motor convulsions.

Histopathologic Correlation: The clinicopathologic features of anti-GAD antibody LE were described in a woman [90] who presented with frequent complex temporal lobe seizures at age 23. Over 8 months there was an evolution of right hippocampal swelling and signal increase on $\mathrm{T}_{2} /$ FLAIR MRI to sclerosis and atrophy. At the time of epilepsy brain surgery CSF showed $10 \mathrm{WBC}$ and oligoclonal bands. Right-sided selective amygdalohippocampectomy of the sclerotic hippocampus showed strong encephalitic features. High-dose corticosteroid therapy administered over several months resulted in seizure-free status until she was weaned off them 2.4 years later when she developed Cushing syndrome. She lapsed into a series of temporal lobe seizures and memory impairment accompanied by temporal left hippocampal swelling for which long-term corticosteroid and azathioprine therapy was started with slow clinical improvement. At follow-up 3.7 years later, she was still experiencing frequent partial temporal lobe seizures with memory deficits.

Bien and colleagues [41] [90] summarized the histopathologic features of selective amygdalohippocampectomy of the sclerotic hippocampus in a patient that included neuronal loss and astrogliosis and a strong accumulation of inflammatory cells in the resected hippocampus. There was marked invasion of the hippocampus by lymphocytes that were mainly CD8+ cells with the cytotoxic effector molecule GrB, in addition to CD20+ cells and CD138+ plasma cells. The pattern of pyramidal cell loss was severe in sectors CA4 and CA3, with selective sparing of CA1 and 2. Surviving neurons were positive for MHC class I, fulfilling the prerequisite for attack by CD8+ cells.

Bien and colleagues [41] quantitated the number of parenchymal T-, B-, and plasma cells, macrophages and glial cells in 3 cases of anti-GAD65 autoantibody LE. Their analysis which included one previously reported case [90], differen- 
tiated anti-GAD65 cases from others with IAg-onconeural autoantibodies (Ma2 in 3 cases; Hu in 4 cases); SAg autoantibodies targeting VGKC-complex (4 cases) and NMDA receptor (3 cases), compared to cases of Rasmussen encephalitis (22 cases) and neurodegeneration controls ( 25 cases). The percentage of CD8+ cells in the IAg-GAD cases was intermediate (54\%) between the IAg-onconeural and $\mathrm{SAg}$ cases. The $\mathrm{CD} 8+/ \mathrm{CD} 3+$ ratio of the $\mathrm{SAg}$ cases was significantly different from the Rasmussen encephalitis controls. That ratio was lower than in the parenchyma confirming that $\mathrm{CD} 8+$ cells migrated more readily into the parenchyma than $\mathrm{CD} 4+$ cells. There was apposition of $\mathrm{GrB}+$ lymphocytes to single neurons consistent with a CD8+ cell-mediated attack in case GAD/3 [90]. Bien and colleagues [41] detected diffuse cytoplasmic IgG detected by anti-human IgG in neurons and astrocytes in all cases similar to that of controls, which they attributed to leakiness of injured neuronal membranes. Staining of C9neo indicative of complement activation was negative in the IAg GAD cases. CD68+ cells comprised $0.2 \%$ in the IAg-GAD cases.

The finding of a reduced CD8+/CD3+ ratio of the IAg-GAD cases, all without concomitant tumor, was lower than the IAg-onconeural group. It was also within the highest ratios of the SAg group of NMDAR cases consistent with the hypothesis that T-cells were a necessary aspect for neuronal loss and hippocampal atrophy in the 2 GAD-associated LE (in GAD cases 2 and 3). Notwithstanding, the absence of underlying cancer could contribute to the long duration of disease and overall less intense inflammation.

As noted by Bien and coworkers [41], the etiopathogenesis of anti-GAD antibodies is uncertain due to the different associated clinical syndromes (SPS, cerebellar ataxia, TLE and LE). Multiple antibodies against IAg and SAg may explain the relatively low $\mathrm{CD} 8+/ \mathrm{CD} 3+$ and $\mathrm{GrB}+/ \mathrm{CD} 3+$ ratios in the $\mathrm{IAg}-\mathrm{GAD}$ cases.

Diagnosis and Treatment: The diagnosis of anti-GAD LE is justified in patients with a clinical syndrome of temporal lobe seizures, and cognitive and psychiatric disturbances, brain MRI abnormalities on $\mathrm{T}_{2}$ FLAIR MRI implicating the medial temporal lobes; CSF pleocytosis and OCB; and EEG revealing temporal lobe epileptic or slow-wave activity, in association with high levels of anti-GAD65 antibodies by RIA. Most cases will fail to disclose an underlying malignancy.

In the series of 58 literature cases summarized by Gangnon and Savard [60] follow-up was available in 53 cases. Full recovery was noted in 4 (8\%) cases, 3 of whom received corticosteroids alone, with intravenous (IV) immunoglobulins, or in combination with PE; a fourth case received no immunosuppressant therapy and recovered. Death occurred in $4(8 \%)$ cases, 3 of whom had an associated cancer. Sustained improvement was noted in $23(43 \%)$ cases with follow-up of 96 months. A favorable outcome was noted in $45 \%$ of cases with positive CSF GAD65 antibodies compared to $56 \%$ of those with antibodies only in serum.

\subsection{Anti-NMDA Receptor Encephalitis}

Background: In 2007, Dalmau and colleagues [91] identified a new CNS antigen 
as NR1/NR2B12 heteromers of the NMDA receptor with predominantly neuropsychiatric symptoms from a cohort of 526 cases of noninfectious LE with antibodies against CNS proteins. The anti-NMDA receptor antibody appears to play a critical role in synaptic plasticity and memory. Although anti-NMDA receptor encephalitis is not by definition associated with cancer, $59 \%$ of patients had a tumor, most commonly benign-appearing cystic mature or immature teratomas tumors of the ovary. All showed serum or CSF antibodies to the NMDA receptor.

A year later, the same investigators [46] described a case series of 100 patients with antibodies against NR1-NR2 heteromers of the NMDA receptor as measured by enzyme-linked immunosorbant assay (ELISA), 91 of whom were women, all with psychiatric symptoms or memory complaints. In addition, seizures were seen in 76 patients; 88 were unresponsive or had altered consciousness, 86 had dyskinesia, 69 had autonomic instability, and 66 showed hypoventilation. Three-quarters presented initially to a psychiatric service.

Epidemiology: Given its characteristic disease course, it is now assumed that a relevant proportion of patients previously diagnosed with encephalitis of unknown origin would have anti-NMDA receptor encephalitis [92] representing about $1 \%$ of all young patients' admissions to intensive care units (ICU). A French study [93] noted a frequency of anti-NMDA receptor encephalitis of $2 \%$ in febrile encephalitis that may be an underestimate because it excluded children. A multicenter, population-based, prospective study showed that anti-NMDA receptor encephalitis accounted for $4 \%$ of case of encephalitis in the United Kingdom (UK) making it the most common cause of AE after acute demyelinating encephalomyelitis (ADEM) in children [94].

Clinical Aspects: Clinically, anti-NMDA receptor encephalitis commences with nonspecific symptoms of headache, fever, nausea, or flu-like illness [95], but over days to weeks, seizures, neurocognitive and neurobehavioral complaints emerge including memory loss and frank neuropsychiatric manifestations of insomnia, mania, anxiety, depression, and paranoia [96] [97]. There can be movement disorders with oro-lingual-facial dyskinesia, autonomic manifestations, central hypoventilation, tachycardia and bradycardia [91] [97]. Autoantibodies targeting the NMDA receptor occur with herpes simplex virus encephalitis (HSVE) [98]. Chorea was noted 10 days to 6 weeks after HSVE [92]. The eventual outcome of all patients was favorable in three-quarters who recovered or had mild deficits with immunotherapy, whereas one-quarter had severe persistent deficits or died. Relapses so noted in $25 \%$ to $30 \%$ of cases [99], were partly attributed to lack of treatment, while $12 \%$ of treated cases relapsed in the first two years in one long-term outcome cohort analysis [100].

Cellular and Synaptic Antibody Effects: Human embryonic kidney cell line 293 (HEK293) that ectopically expresses single or assembled NR1-NR2 subunits was used to determine the extracellular N-terminal domain of the NR1 subunit epitope targeted by the anti-NMDA receptor antibodies. By quantitative analysis of the NMDA receptor in neuronal cell culture, there was a decrease in the 
numbers of cell-surface NMDA receptor, and NMDA receptor clusters in postsynaptic dendrites. Most patients with anti-NMDA receptor encephalitis have intrathecal synthesis of antibodies and numerous plasma cells in perivascular, interstitial, and Virchow-Robin spaces with complement fixing IgG and IgG3, as well as B- and T-cells in perivascular regions. Complement-mediated mechanisms in anti-NMDA receptor encephalitis studied in cultured rat hippocampal neurons tested for complement fixation [101] showed complement binding in vitro and in neural tissue of teratoma tumors, although not in the brains of affected patients.

Laboratory Investigations: Testing for anti-NMDA receptor antibodies is recommended in patients who manifest encephalitic signs, psychiatric symptoms, seizures, and CSF inflammation, after exclusion of viral and bacterial causes of infection regardless of neuroradiologic investigation since the disorder may be associated with normal MRI findings in up to $50 \%$ of cases. The remaining one-half may include non-specific changes and abnormal $T_{2} /$ FLAIR MRI hyperintensities in the mesial temporal lobe, cerebral or cerebellar cortex, basal ganglia or brainstem. There is typically no abnormal enhancement or hemorrhage. FDG brain PET may show hyper- or hypometabolism in the affected regions [102]. Up to $25 \%$ of patients have electrographic seizures [100]. CSF analysis can show moderate lymphocytic pleocytosis, increased protein content, elevated IgG index, and CSF-specific oligoclonal bands [103] which were typically negative at first testing, but can become positive later with disease progression in up to one-half of cases [99].

Histopathologic Correlation: The histopathologic aspects of NMDA receptor encephalitis were studied in 14 cases [41] [46] [101] [104] [105] [106] [107] including 9 at postmortem examination [101] [104] [107] and 5 in brain biopsy tissue [41] [101] [107]. Dalmau and colleagues [104] described 12 women with prominent neuropsychiatric symptoms, seizures, dyskinesia, autonomic dysfunction and altered consciousness. All had elevated serum/CSF antibodies that immunolabeled the neuropil of the hippocampus and forebrain, especially the cell surface of hippocampal neurons that reacted to NR2B, and a lesser extent the NR2A subunits of the NMDA receptor. Expression of functional heteromers, not single subunits, is required for antibody binding. The CSF and serum of all 12 patients showed a distinctive pattern of reactivity within the neuropil of rat hippocampus, and intensively immunolabeled the cell membrane of neurons in the molecular layer of the hippocampus. Three patients age 14, 24 and 35 years of age (Cases 2, 6, 10) died, including one (Case 10) previously reported [105], 3 to 6 months after symptom presentation. MRI showed $\mathrm{T}_{2} /$ FLAIR hyperintensities in the medial temporal lobes (Case 2); hyperintensities of the parietal sulci and enhancement of overlying meninges (Case 6); and a third (Case 10) showed normal findings. CSF in all three showed pleocytosis varying from 115 (Case 10) to 219 WBC (Case 6) with minimally increased or normal protein content, and positive oligoclonal bands. Immunofluorescence microscopy experiments demonstrated co-localization of antigens reacting with patient antisera and antibo- 
dies against NR2B, and co-localization of these antibodies in patients' tumor samples and in brain. Postmortem examination showed extensive gliosis, rare T-cell infiltrates, and neuronal degeneration predominantly involving, but not restricted to the hippocampus in all three. These findings predominated in the hippocampus but affected other areas of the brain, brainstem, and spinal cord. There was intense IgG immunostaining of the hippocampi resembling rodent-staining of NMDA receptor in brain sections without complement immunostaining. Subsequent studies by the same author [46] employing HEK293 cells determined that the main epitope targeted by the antibodies was the extracellular N-terminal domain of the NR1 subunit. Patients' antibodies reduced the density of cell-surface NMDA receptor and clusters in postsynaptic dendrites, an effect that reversed by antibody removal. Tüzün and coworkers [106] extended the immunopathological analysis of Cases 6 and 10 reported previously by Dalmau and colleagues [104] noting that lymphocytic infiltrates were uncommon, and were rarely noted in the perivascular and leptomeningeal regions or scarcely distributed in the brain parenchyma. B-cells and plasma cells were identified in the perivascular space including $1 \%$ cytotoxic T-cells, with absence of $\mathrm{GrB}+$, Fas and Fas ligand-positive cells were noted in all areas of the CNS but most intensely in the hippocampus, basal forebrain, and cervical cord. Using HEK293 cells expressing NR1/NR2B, the NMDA receptor IgG was mainly $\operatorname{IgG}_{1}$, but included $\mathrm{IgG}_{2}$ and $\mathrm{IgG}_{3}$ types. Tumor samples expressed NR1/NR2-expressing tumor cells in varying amounts.

Camdessanché and coworkers [107] reported the postmortem findings of a brain biopsy specimen from an 18-year-old woman with anti-NMDA receptor encephalitis who presented with subacute mood changes and facial jerks. Brain MRI showed $T_{2}$ hyperintense foci in the right frontal lobe, and CSF showed 21 WBC and oligoclonal bands. A frontal lobe biopsy showed perivascular cuffing of B-cells and a few plasma cells, with few T-cells or macrophages scattered throughout grey and white matter and in perivascular spaces. Retrospective screening for anti-NMDA receptor antibodies was performed on a CSF sample that was positive at a dilution of 1:10, both in the neuropil of the rat hippocampus and in transfected HEK293 cells.

Martinez-Hernandez and coworkers [101] described 2 men, age 7 and 59 years, and three women age 5, 24 and 35 years, the latter two with ovarian teratomas, and anti-NMDA receptor encephalitis who presented with subacute short-term memory deficits, psychiatric disturbances, seizures, movement disorders, and dysautonomia ranging from 22 days to 4 months. CSF showed protein elevation ranging from 94 to $219 \mathrm{mg} / \mathrm{dL}$ with oligoclonal bands. Brain MRI showed increased FLAIR signal in medial temporal lobes (Case 1), parietal cortex (Case 2), left temporal cortex (Case 3), as well as the insula and anterior temporal lobes with atrophy (Case 5); brain MRI was normal in Case 4. Treatment with combined immunotherapy in one patient who underwent a brain biopsy was effective, while the others died. One patient who died underwent earlier brain biopsy, and the remaining three patients were studied at postmortem 
examination. Patients' antibodies were able to fix complement on cultures of rat hippocampal neuron but were not detected in any of the brain regions of 3 patients, or in biopsies of 2 patients, all with anti-NMDAR encephalitis. The main histological findings were an abundance of infiltrating plasma cells and plasmablasts in perivascular regions cuffing blood vessels, Virchow-Robin spaces, and lining the meningeal-brain surface in proximity to the CSF. Using cultures of rat hippocampal neurons, the patients' antibodies were able to fix complement but deposits of IgG were absent, nor was there complement immunostaining at postmortem examination or in brain tissue biopsies. In contrast to brain, tumor neural tissue showed complement immunoreactivity.

Bien and colleagues [41] examined brain biopsy tissue from 2 women and 1 man, age 17 to 22 years with NMDA receptor encephalitis, all three with encephalopathy lasting 2 months to 12 months, none with an associated tumor. Two were treated with immunotherapy before frontal (2 patients) or temporal lobe cortical biopsy. Serial MRI in one patient did not show hippocampal atrophy. Histopathology of the tissue specimens showed low density of T-cells, in the range of neurodegeneration controls. The ratio of perivascular $\mathrm{CD} 8+/ \mathrm{CD} 3+$ was slightly elevated, and there were cytotoxic granules in some parenchymal T-cells, but no apposition of CD8+ cells to single neurons. Diffuse cytoplasmic IgG was evident in both neurons and astrocytes and C9neo deposition was expressed in the cytoplasm and on the surface of hippocampal CA4, dentate, and cortical neurons. The neocortex of anti-NMDA receptor antibody-positive patients showed almost no inflammation, and no clear signs of neuronal loss. Even though anti-NMDA receptor antibodies appeared to be involved in the clinical disease process, there was no evidence to suggest a classical mechanism of cytotoxic T-cell or humoral immune-mediated neuronal cell death. The possibility of a more active inflammatory infiltrate and antibody deposition at an earlier disease stage in both the hippocampus and cortex could not be excluded, although it was striking that MRI evidence of inflammation in the hippocampus was rare.

Collectively, the histopathologic findings were consistent with a selective and reversible decrease in NMDA receptor surface density and synaptic localization that correlated with patients' antibody titers. The mechanism of this decrease was selective antibody-mediated capping and internalization of surface NMDA receptors. This was supported by the experimental finding of Hughes and colleagues [108] who studied Fab fragments prepared from patients' antibodies that did not decrease surface receptor density. Subsequent cross-linking with anti-Fab antibodies recapitulated the decrease caused by intact patient anti-NMDA receptor antibodies. These cellular mechanisms appear to be the cause of the specific titer-dependent and reversible loss of NMDA receptors. The loss of the subtype of glutamate receptors that eliminates NMDA receptor-mediated synaptic function may underlie the learning and memory deficits observed in affected patients.

Diagnosis and Treatment: Suggested criteria for the definite diagnosis of anti-NMDA receptor encephalitis [109] includes the presence of IgG anti-GluN1 
antibodies in a suspected patient with subacute onset of psychiatric behavior or cognitive disturbances, seizures, movement disorder, autonomic dysfunction; and abnormal EEG that shows focal or diffuse slowing or epileptic activity; and CSF pleocytosis or oligoclonal bands.

Prompt diagnosis of anti-NMDA receptor encephalitis leads to improvement typically after removal and treatment of an offending cancer, or in the absence thereof. The demonstration of copious infiltrates of antibody-secreting cells in the CNS of affected patients provides an explanation for the intrathecal synthesis of antibodies, and implications for treatment used to arrest and reverse the disorder employing IV immunoglobulins, corticosteroids, cyclophosphamide, or rituximab.

Given its characteristic disease course, it is now assumed that a relevant proportion of patients previously diagnosed with encephalitis of unknown origin would have anti-NMDA receptor encephalitis [92] representing about $1 \%$ of all young patients' admissions to ICU. A French study [93] noted a frequency of anti-NMDA receptor encephalitis in $2 \%$ in febrile encephalitis that could be an underestimate because of the exclusion of children. A multicenter population-based prospective study showed that anti-NMDA receptor encephalitis accounted for $4 \%$ of case of encephalitis in the UK, making it the most common cause of AE after ADEM in children [94].

\subsection{Anti-VGKC-Complex Encephalitis}

Background: About the same time that MoS was described, anti-VGKC-complex antibodies were determined using by Buckley [36], Schott [110], Thieben [111] and Vincent and coworkers [33] using RIA in patients with noninfectious AE. While the disorder was generally termed LE, the term limbic encephalopathy was also used as more patients were found to be seropositive without evidence of classical features of hyperintense signal intensities in the medial temporal lobes on brain MRI, and CSF inflammation [33] [112].

Alteration of trans-synaptic scaffolding systems in AE that affects neuronal cell adhesion molecules are crucial for proper synapse formation and adhesion, plasticity, and function. In both developing and mature neurons, these molecules serve to recruit and anchor pre- and postsynaptic proteins to appropriate synaptic localizations, allowing for normal synaptic transmission. Autoantibodies against the VGKC-complex detected by RIA in the sera of patients with AE do not bind directly to VGKC-complex channel proteins proper, but instead to synaptic and axonal neuronal proteins that coprecipitate with detergent-solubilized VGKC [113] [114].

Attention has focused on identifying the principal autoantigens in the VGKC-complex and expanding the spectrum of corresponding phenotypes. Initial reports [115] [116] suggested that patient antibodies were bound to the VGKC Kv1.1 and Kv1.2. Subsequent studies showed that leucine-rich glioma-inactivated protein 1 (LGI1) LGI1, and contactin-associated protein-like2 (Caspr2) were the main autoantigens [113] [114] [117] associated with transiently expressed axonal 
glycoprotein (TAG1), post synaptic density protein-Drosophila disc large tumor suppressor-zonula occludens-1 protein (PDZ), and ankyrin-spectrin protein, in both the peripheral and CNS. Antibodies against contactin-2 usually occur in association with those targeting LGI1 or Caspr2 were identified in other disorders [118] raising doubts about their importance. There is both diversity and overlap of neurological phenotypes associated with VGKC-complex-IgG in the serum and CSF, and distinctive Ig-subtype specificity. The most common presentation of VGKC-complex autoantibodies is LE in the CNS [119].

Epidemiology: In the UK, where the incidence of encephalitis is estimated at 5.23 cases/100,000/year based upon admissions to the National Health Service between 2005 and 2009, Granerod and colleagues [120] estimated the incidence of encephalitis as 4.32 cases/100,000 population/year. A capture-recapture model estimated the incidence of encephalitis to be 8.66 cases/100,000/year. Two percent of patients $(\mathrm{n}=216)$ had $>1$ encephalitis admission during the study period; and the incidence did not change (4.20 cases/100,000/year) when subsequent admissions of these patients were excluded from the analysis. By using data restricted to the primary diagnostic field, the overall mean incidence was 2.75 cases/100,000/year (95\% CI 2.39 cases-3.10/100,000/year). The results of multivariable analyses showed that compared with 2005-2006, incidence in all subsequent years was slightly higher but with little evidence of a trend $(P=0.19)$. The incidence rate was highest among patients $<1$ year of age, and in those $>65$ years of age. A retrospective study that reviewed antibodies to VGKC, LGI1 and Caspr2 in 46 children with severe acute encephalitis identified only one affected child (2.2\%) among 46 children [121].

Clinical Aspects: Among 64 patients with VGKC-complex encephalitis [122] the clinical features overall included neuropsychiatric features, disorientation, confusion, or amnesia in $100 \%$ of patients; tonic-clonic seizures in $92 \%$, delusions in $21 \%$, hallucinations in $17 \%$, agitation in $6 \%$, pain in $4.7 \%$, and peripheral neuropathy in $1.6 \%$ of cases. Neurocognitive complaints, psychiatric symptoms and seizures [33] [99] [111] typically evolved over days to weeks, occasionally acutely, but more often insidiously over months before coming to medical attention.

The finding of an apparent dementia in 72 affected patients was studied by Flanagan and colleagues [123]. Responsiveness to immunosuppressant and immunomodulatory therapy was predicted by seropositivity for neuronal VGKC-complex antibody more than calcium channel or neuronal acetylcholine receptor $(P=0.01)$. Up to $40 \%$ of patients may also manifest frontal lobe and frank psychiatric features.

Parthasarathi and colleagues [112] described a 58-year-old man with panic attacks and psychogenic non-epileptic seizures who later developed delusions and hallucinations followed by confusion. He was found to have VGKC-complex antibodies and treated with immuno-modulatory therapy leading to near complete recovery. Bettcher and coworkers [124] delineated cognitive strengths and weaknesses among 12 subjects with VGKC-complex encephalitis noting mild to 
moderate impairment in memory and executive functions, with variable impairments in language and sparing of visuospatial skills that correlated with MRI findings of $T_{2}$ /FLAIR hyperintensities in medial temporal lobe (10/10) and basal ganglia (2/10). Serial cognitive examination revealed heterogeneity in cognitive function.

Seizures that occur in up to $90 \%$ of cases are most commonly focal in nature, with infrequent generalization, manifesting typical medial temporal lobe signature with hand and orofacial automatisms. Three seizure semiologies, ictal bradycardia, piloerection, and fasciobrachial dystonic seizures (FBDS), show a strong associations to LE associated with LGI1 antibodies. FBDS consist of brief frequent episodes abnormal unilateral and bilateral movements of the arms, sometimes the ipsilateral muscles of the face, and more rarely the leg. Video electroencephalography shows an epileptic origin of these myoclonic-like movements however regular EEG with scalp electrodes often misses an interictal focus. If FBDS are recognized early, and serum LGI1 antibodies are detected, immunotherapy prevents progression to frank LE, which in one study arose after a median delay of 36 days [125].

Kalachikov and investigators [126] described autosomal dominant lateral temporal epilepsy (ADLTE) characterized by partial seizures and preceding auditory signs in the LGI1/epitempin gene expressed on chromosome 10q24. Mutations in this gene introduced premature stop codons and prevented production of full-length protein from the affected allele. Although LGI1 haplo-insufficiency leads to ADLT, the underlying molecular mechanism that results in abnormal brain excitability was attributed to dysregulation of synaptic hippocampal AMPA receptors in the epileptic LGI1 knock-out mouse [127]. Fukata and colleagues [128] proposed that extracellular secreted LGI1 linking two epilepsy-related brain receptors, a disintegrin and metalloproteinase domain 22 (ADAM22) and ADAM23, organize a transsynaptic protein complex that contains presynaptic potassium channels and postsynaptic AMPA receptor scaffolds. A lack of LGI1 disrupts this synaptic protein connection and selectively diminishes AMPA receptor-mediated synaptic transmission of the hippocampus.

Younger and colleagues [129] described new-onset FBDS and memory disturbances in association with large and small fiber peripheral neuropathy and dysautonomia without systemic malignancy in a patient with extrathecal VGKC-complex antibody production. Sleep disorders were noted in a group of patients with antibodies to VGKCs, without further specification of the target antigen [130]. Affected patients with LE may develop myoclonic movements resembling Creutzfeldt-Jakob disease [113] [131].

Klein and coworkers [132] noted neuropathic pain associated with VGKC-complex autoimmunity in $4 \%$ patients evaluated neurologically at a tertiary referral center that was generally subacute in onset and regional or diffuse. Among those suspected of peripheral neuropathy with mild subjective loss of temperature and pain attributed to small fiber dysfunction, electrodiagnostic studies showed variable minor reduction of sural sensory nerve action potential 
amplitudes with motor hyperexcitability. VGKC-complex antibody titers were often low $(0.02-0.1 \mathrm{nM})$ in such cases, and antibodies to LGI1 or Caspr2 were present in $28 \%$ overall, with the latter most common (7\%). Bennett and Vincent [133] conjectured that VGKC-complex antibodies led to enhanced excitability of the somatosensory system. Caspr2 is an adhesion molecule that forms a complex with Kv1.1 and 1.2 in the juxtaparanodal region of the node of Ranvier with a capacity of modulating the internodal resting potential. It affects the soma of C-fiber nociceptors that express VGKC currents, blockade of which could alter neuronal excitability. Analogously, voltage-gated sodium channels are responsible for the generation and conduction of action potentials along peripheral nociceptive neuronal pathways where $\mathrm{NaV} 1.7, \mathrm{NaV} 1.8$, and $\mathrm{NaV} 1.9$ sodium channels are encoded by SCN9A, SCN10A, and SCN11A [134].

Autonomic involvement was noted in $29 \%$ of the cohort studied by Klein and colleagues [132], and in $3(60 \%)$ of the patients described by Lahoria and coworkers [135]. Hypothermia was described in association with VGKC-complex antibody-associated LE in 4 patients [37], Patient 1 of whom had concomitant neuropathic patient, and in the absence thereof in the others who were conjectured to have otherwise disturbed hypothalamic thermoregulatory mechanisms as the cause for dysautonomia.

Cellular and Synaptic Antibody Effects: According to Lancaster and Dalmau [136], LGI1 is a secreted synaptic protein that associates with, and regulates Kv1.1 and Kv1.2, as well as AMPA [128]. Caspr2 is a transmembrane axonal protein of the neurexin IV superfamily that localizes to the juxtaparanode of myelinated axons, and its extracellular domain interacts with contactin-2 [137] where it connects with the cytoskeleton via protein 4.1B. Caspr2, contactin-2 and protein $4.1 \mathrm{~B}$, all of which are necessary to concentrate Kv1.1 and Kv1.2 channels in the juxtaparanode. Lai and colleagues [113] [117] studied proteins associated with Kv1.1 and Kv1.2, noting that VGKCs themselves were the autoantibody targets, explaining the diversity of symptoms among patients with these antibodies. LGI1 is primarily a CNS protein, and LGI1 antibodies are associated with LE, seizures, and hyponatremia.

Lancaster and Dalmau [136] also observed that LGI1 antibodies caused reversible CNS synaptic dysfunction by several mechanisms. The antibodies may prevent binding of LGI1 to the receptors that it regulates, or they might act on the LGI1-ADAM protein complex. Alternatively, LGI1 antibodies could disrupt currents mediated by Kv1.1 and Kv1.2, and/or impair AMPA receptor function, either indirectly by blocking LGI1-mediated regulation of these proteins or directly by disrupting the entire protein complex. A study involving application of serum from a patient with LGI1 antibodies to a hippocampal slice preparation showed effects similar to application of a Kv1.1 and Kv1.2 antagonist [138]. The identification of LGI1 as a major target of so-called VGKC antibodies clarifies several aspects of the associated disorder.

Lancaster and Dalmau [136] further noted that Caspr2 antibodies were associated with autoimmune encephalitis, peripheral nerve hyperexcitability, and 
MoS. Peripheral nervous system manifestations may precede or follow those of the CNS by up to several years. Some affected patients may have an associated thymic tumor, but most do not. Mutations in the human gene encoding Caspr2 (CNTNAP2) are associated with autism, epilepsy, Tourette syndrome, cortical dysplasia, obsessive-compulsive disorder, Pitt-Hopkins syndrome, and other mental disabilities [139] [140] [141]. Mice with a Caspr2 deletion show analogous behavioral defects and symptoms [142]. Interestingly, common variants of the CNTNAP2 gene in healthy individuals are associated with abnormal language processing and are a risk factor for autism [143]. Caspr2 antibodies act by disrupting axonal potassium currents. Factors such as differences in time to establishment of intrathecal antibody synthesis, or in the structure of tight, septate-like junctions of myelinating cells around the axons may explain this variability. The VGKC-complex antibody levels also broadly differ between the different syndromes, with highest levels in LE and FBDS, moderate levels in MoS, and lowest levels (often $<400 \mathrm{pM}$ ) in PNH.

Laboratory Investigation: The high proportion of VGKC-complex IgG-seropositive patients' samples that lack LGI1 IgG and Caspr2 IgG specificities suggests that other VGKC-complex molecular targets remain to be discovered. With up to $5.5 \%$ of unselected cases seropositive by RIA with confirmatory retesting using ${ }^{125} \mathrm{I}-\alpha$-dendrotoxin alone (radioligand for Kv1.1, Kv1.2, and Kv1.6 channels) [119] [144] [145], the test is unreliable as a screen for LE without further subtyping for LGI1 and Caspr2-IgG. And with up to 28\% [3] [19] of seropositive VGKC sera reactive with LGI1 and/or Caspr2-IgG, there was a significant association between LGI1-IgG-positivity and cognitive impairment and seizures $(P<$ $0.05)$, and Caspr2-IgG-positivity and peripheral motor excitability $(P=0.004)$ [3]. Graus and Gorman [146] expressed concern for the screening of unselected sera for VGKC-complex antibodies by RIA arguing that the VGKC-complex RIA antibody test could be employed in initial screening to select positive samples that could then be confirmed by LGI1 or Caspr2-IgG antibody subtyping. The latter subtyping were also positive in selected VGKC-complex antibody-negative sera by RIA [145] [147]. Paterson and colleagues [148] noted seropositive VGKC-complex antibody values ( $>400 \mathrm{pm}$; $>0.4 \mathrm{nM}$ ) that could be relevant in LE, as well as low-positive values $(<400 \mathrm{pm} ; 0.1-0.4 \mathrm{nM})$ in cases considered to be non-autoimmune, $13 \%$ of which had a definite or probable associated paraneoplastic neurologic disorder, neuromyotonia or MoS. Ances and colleagues [49] noted that the RIA used in the clinical analysis of VGKC-complex antibodies identified a limited number of subunits (Kv1.1, Kv1.2 and Kv1.6) but that it was reasonable to speculate that antibodies to other subunits, $\mathrm{K}+$ channel families and VGKC ion channels might also associate with LE [33].

Cerebral imaging studies in VGKC-complex antibody associated LE show highly variable results. Both mesial temporal lobe hypometabolism on FDG brain PET [149] [150] and hypermetabolism have been described [151]. A patient with VGKC-complex LE [150] who did not definitively demonstrate structure abnormalities on serial brain MRI over time despite ongoing temporal lobe 
seizures that was captured on video-EEG later showed bitemporal hypometabolism on FDG brain PET fused with gadolinium-enhanced MRI. Further, Baumgartner and colleagues [151] identified 9/18 (50\%) patients positive for non-paraneoplastic antibodies against neuronal surface antigens (VGKC or NMDA-R), 2 of whom displayed mesiotemporal hypermetabolism on FDG brain PET, with 4 others were rated normal, and 3 displayed hypermetabolism outside the mesiotemporal region. The fraction of abnormal scans employing MRI was lower (10/16; 62.3\%) than FDG brain PET (14/18; 77.7\%).

According to Jarius and colleagues [152], who performed 29 lumbar punctures in 17 patients with VGKC-complex LE, noting normal findings in up to $53 \%$ of CSF specimens. There were no significant differences between the CSF findings and the titers of serum VGKC-complex autoantibodies. Slight pleocytosis, mainly consisting of lymphocytes and monocytes, and elevated total protein concentrations were present in $41 \%$ and $47 \%$, respectively. A disturbance of the integrity of $\mathrm{BBB}$ was found in 6 (35\%) patients based upon an abnormal CSF/ serum humoral immune response. Absence of CSF-specific OCB, considered a marker of autochthonous antibody synthesis within the CNS in all patients [152] suggested an extrathecal origin of VGKC-complex autoantibodies. Vincent and colleagues [33] reported the CSF findings in 10 patients, all with VGKC-complex antibody-associated LE, noting mild lymphocytosis and mild or moderately raised protein content in one-half. OCB were noted in 1 patient, while 6 other OCB were identical to serum. VGKC-complex antibody assays on matched serum and CSF showed antibodies levels of the latter present in 4 patients that varied between $<1 \%$ and $10 \%$ of the serum, and beneath $10 \%$ in one patient with the lowest serum value.

Ten positive sera retested for binding to rat brain sections revealed five that were strongly seropositive by RIA and immunohistochemistry were directed mainly against Kv1.1 and Kv1.2 subtypes of VGKC present in the molecular layer of the dentate gyrus of the hippocampus [36] [153] [154]. These findings were consistent with extrathecal synthesis of VGKC-complex antibodies. Abnormalities so noted in cases of VGKC-complex antibodies-associated FBDS [129] and others with LGI1-antibody LE [125] may explain the passage of extrathecally-derived VGKC-complex antibodies across a disrupted BBB.

Irani and Vincent [122] estimated a prevalence of peripheral neuropathy in $1.6 \%$ of patients. Among five patients with VGKC-complex autoantibodies ranging from 0.08 to $1.18 \mathrm{nM}$ [135], only two had antigens positive for Caspr2 and LGI1-IgG, both at low titers [respectively 0.08 and $0.16 \mathrm{nM} / \mathrm{L}$ ). Electrodiagnostic studies revealed distal polyneuropathy that was concordant with abnormal indices of axonal degeneration or demyelination in 4 nerves, and the latter with quantitative analysis of semithin sections in 2 . All five had absence of inflammatory cell infiltration on histopathologic nerve studies. By comparison, the symptoms of small fiber neuropathy, which arise from dysfunction in nociception, temperature and autonomic modalities [155], and most adequately assessed by epidermal nerve fiber density in a $3 \mathrm{~mm}$ punch biopsy of skin from the later 
calf and thigh [156] and a combination of cardiovagal, sudomotor and adrenergic functions tests [157], have only recently been reported.

Histopathologic Correlation: Eight patients with VGKC-complex LE were studied histopathologically, including stereotactic brain biopsy in 3 [33] [41] at epilepsy surgery in 1 case [41], and at postmortem examination in 4 patients [41] [158] [159] [160]. Vincent and colleagues [33] described a 56-year-old man with 7-month history of confusion and memory impairment who developed partial focal seizures, anxiety and delusions. CSF showed mild pleocytosis and brain MRI showed unilateral left medial temporal lobe signal change with focal slow activity on EEG. The serum VGKC antibody titer was $2224 \mathrm{pM}$ (normal 0 $100 \mathrm{pM} ;>400 \mathrm{pM}$ highly elevated). Histopathology of a stereotactic biopsy of the left amygdala showed positive staining for perivascular and parenchymal CD45+ lymphocyte infiltrates, astrogliosis, and CD68+ microgial activation. He received a course of intravenous dexamethasone with a slight beneficial response with persistent memory deficits. Follow-up brain MRI showed evolution of bilateral hippocampus atrophy and signal changes.

Dunstan and colleagues [158] reported a 78-year-old man with a two week history of confusion, cognitive impairment and hyponatremia. Brain MRI showed increased signal in the right medial temporal lobe with subcortical white matter changes. Cerebrospinal fluid was normal. Assay for VGKC antibodies were 1637 pM by RIA. He received anticonvulsants but deteriorated due to sepsis and died. Postmortem examination showed no evidence of a malignancy. The brain showed severe neuronal loss with multiple reactive astrocytes, macrophages, and scattered T-cells in the right amygdala nucleus and adjacent hippocampus.

Park and coworkers [159] described a 65-year-old woman with a three month history of amnesia, disorientation, memory loss, and partial complex seizures. Brain MRI was normal and CSF showed 17 WBC. EEG showed mild diffuse slowing. She later developed hyponatremia and serum VGKC-complex antibodies were $1.73 \mathrm{nmol} / \mathrm{L}$ (normal $<0.02 \mathrm{nmol} / \mathrm{L}$ ) by RIA. Whole body FDG-PET showed mediastinal adenopathy. She was treated with intravenous corticosteroids for 5 weeks without improvement and later died. General autopsy limited to the chest showed no malignancy. Postmortem examination of the brain showed mild focal perivascular T-cell lymphocyte cuffing and infiltrates of overlying meninges and parenchyma of the cingulate gyrus, hippocampus, and amygdala and midbrain.

Khan and coworkers [160] reported a 56-year old man with a four month history of confusion, disorientation and seizures. A serum VGKC antibody titer was 3327 pM by RIA and there was hyponatremia. Brain MRI showed left hippocampal atrophy on $\mathrm{T}_{2} /$ FLAIR images. General postmortem examination showed no malignancy. Examination of the brain showed pathological changes in both hippocampi and right amygdala regions comprised of pyramidal neuronal cell loss in the CA4 region, marked activation of CD68+ microglia and reactive GFAP+ astrocytosis extending to the subiculum, less so near the joining 
of the parahippocampus gyrus. There were perivascular infiltrates of CD20+ B-cells and a few CD4+ T-cells especially in the right hippocampus.

Bien and colleagues [41] summarized the histopathologic findings in the brain in four patients, including 3 men and 1 woman, age 33 to 68 years, with LE ( 3 patients) and multifocal encephalitis in another, ranging from 5 to 9 months. Serum VGKC antibody titers were 167, 288, 958 and 2224 Pm respectively. Serial MRI showed an evolution from hippocampal swelling with $T_{2}$ /FLAIR signal increase to frank hippocampal atrophy and increased signal intensities. Histopathologic examination including quantitative immunocytochemical studies showed variable intense inflammation and lower $\mathrm{CD} 8+/ \mathrm{CD} 3+$ ratios, with $\mathrm{GrB}+$ $\mathrm{T}$-cells in the lesions without opposition to neurons or release of $\mathrm{GrB}$, therefore T-cell cytotoxicity was not a major contributor. Immunoglobulin and complement deposition on neurons was a prominent finding, and terminal deoxynucleotidyl transferase dUTP nick and labelling (TUNEL) reaction in the same area indicated acute neuron cell death suggesting antibody and complement-mediated neuronal cell damage. The authors [41] noted that IgG4 rather than IgG1 antibodies dominated in the sera of those with VGKC-complex LE. In light of the finding that immunoprecipitated dendrotoxin-labelled VGKC-complexes directed at GGI1, Caspr2 and other undefined components of the VGKC-complex [113] [99], it is notable that one of the 3 cases with C9neo deposition was LGI1 seropositive, while the second was negative for both LGI1 and Caspr2. A third case that showed extensive C9neo deposition on neural somata and neuronal death was serologically indeterminate.

Diagnosis and Treatment: Suspected patients with new-onset and rapid progression of memory deficits, seizures, or psychiatric symptoms suggesting involvement of the limbic system; with bilateral medial temporal lobe abnormalities on T2/FLAIR MRI; and CSF pleocytosis, combined with TLE or slow-wave activity on EEG should be screened for VGKC-complex antibodies, with detection of LGI1 and CSFPR2 by RIA. The diagnosis of VGKC-complex LE can be established in suspected cases when serological studies are combined with clinical, neuroradiologic and CSF inflammatory parameters, and a reasonable exclusion of alternative diagnoses. If so, immunomodulatory and immunosuppressive therapy should begin. Less than one-half of affected patients fail to improve with first-line therapy employing IV immunoglobulins, plasma exchange, or corticosteroids, needing to advance to second-line agents including cyclophosphamide and rituximab.

Bataller and colleagues [161] noted that treatment-responsiveness of LE was favorable among patients with antibodies to the VGKC-complex with overall improvement in two-thirds of patients. However, a favorable response to therapy was not limited to patients with VGKC-complex antibodies but extended to novel-cell-membrane antigens ( $\mathrm{nCMAg}$ ) expressed in the hippocampus. If the autoantigens were unknown but found to be highly enriched in neuronal cells membranes of the hippocampus, the respective antibodies were associated with a favorable outcome emphasizing the usefulness of immunohistochemistry in the 
analysis of highly-suspected patients with LE. The salutary effect of immunotherapy in the management of seizures in VGKC-complex antibody-associated LE is well supported by the autoimmune basis of FBDS [162].

\subsection{AMPA Encephalitis}

Background: In 2009, Lai and colleagues [163] characterized antibodies to GluR1 and 2 in 10 patients with LE that was often paraneoplastic yet treatment-responsive with a likelihood of relapse and antibody-mediated pathogenesis in which the patients' antibodies altered the synaptic localization and number of AMPA receptors (AMPAR). Further studies by the same authors [164] in a larger cohort highlighted the presence of prominent neuropsychiatric features.

Epidemiology: This is a rare disorder and probably underreported with few cases and no large series from which to draw reliable population incidence estimates.

Clinical Aspects: Among 10 patients with AMPA encephalitis described by Lai and colleagues [163], the median age of nine affected women and one man was 60 years (age range 38 - 78 years), who presented with subacute confusion, disorientation, short-term memory loss, and personality change. Four patients developed seizures. Neurological examinations were consistent with limbic encephalopathy. The clinical presentation among 22 additional patients [164] the most frequent presentation was also LE in 10 patients, however in ten patients, other symptoms heralded or accompanied LE including, seizures, behavioral change, psychosis, spasticity, optic neuropathy, sensory neuropathy, ataxia, behavioral change, aphasia, hemiparesis, involuntary movements, and autonomic dysfunction.

Cellular and Synaptic Antibody Effects: Antibodies to the ionotropic AMPAR target SAg of the GluA1 or Glu2 subunits, important in fast excitatory input to the brain [165]. Lai and colleagues [163] employed immunoprecipitation to identify the primary antigens that manifested distinctive protein bands of about $100 \mathrm{kDA}$, which when analyzed by mass spectrometry, showed sequences derived from the GluR1/2 subunits of AMPAR. Western blot analysis confirmed that the band precipitated by patients' antibodies contained the GluR1 and GluR2 subunits. Such antibodies were present in paired serum and CSF samples with intrathecal synthesis. All affected patients' serum or CSF samples show intense neuropil staining on brain tissue immunohistochemistry and react with HEK cells co-expressing GluA1/2 subunits of AMPA receptor. Manifesting tumors expressed the same subunits by immunohistochemistry. Antibody binding to the receptor, with capping and internalization led to a decrease in synaptic AMPAR activity. Removal of antibodies from neuronal cultures restored receptor numbers and localization of AMPAR clusters [163]. Located in hippocampus and outer cortex, olfactory regions, lateral septum, basal ganglia, and amygdala [166], AMPAR trafficking plays a role in long-term potentiation (LTP) important in long-lasting increase in signal transmission between neurons forming the substrate for memory and learning. Brain-derived neurotrophic factor (BDNF) 
activates the kinase, mechanistic target of rapamycin (mTOR) that regulates GluR1 expression required for memory formation. A consequence of blocking of AMPARs is interruption of the learning process [167]. The disorder was paraneoplastic in association with thymoma, SCLC, and breast cancer [163], so noted in seven patients, including 5 diagnosed by the time of initial episode of LE, and 2 patients at first relapse of LE. Other cancers in addition included ovarian teratoma and thymus carcinoid tumors [164].

Laboratory Investigation: In 11 of 12 patients described by Höfrberger and colleagues [164] who presented with LE, MRI showed unilateral (2 cases) or bilateral ( 9 cases) medial temporal increased $\mathrm{T}_{2} /$ FLAIR signal abnormalities. EEG showed epileptiform activity in 5 patients, focal temporal slowing in 1 , and diffuse slowing in 3 patients. CSF was abnormal due to pleocytosis in 5 patients or increased protein in 2 patients, with both together in 1; and normal 4 patients.

Additional neuronal antibodies were found in six patients, including 3 each targeting the IAg-onconeural antibodies CRMP5 and amphiphysin; and SAg determinants on the GABAB receptor and NMDA receptor; the majority with associated tumors. In nearly all cases, the resulting clinical phenotypes were determined by the associated antibody-immune response rather than that of the AMPAR antibody syndrome.

Histopathologic Correlation: Two patients (Autopsy Case 5 and 9) died and underwent postmortem examination [163]. The first patient, a 44-year-old woman with rapidly progressive change of behavior and confusion had an enlarged mediastinum, and serological studies demonstrating CV2/CRMP5 onconeural antibodies. She died of other causes. At postmortem examination, there was a thymoma. Neuropathological findings in the brain were consistent with LE including perivascular and interstitial inflammatory infiltrates, microglial proliferation, and astrocytosis that largely predominated in the hippocampi. Some of the interstitial infiltrates surrounded neurons, forming neuronophagic nodules, and were predominantly composed of CD8+ T-cells that expressed TIA-1. Autopsy Case 9, a 59-year-old woman with progressive memory loss and behavioral change died of other causes after clinical recovery of LE of other causes was free of systemic cancer. Neuropathological studies limited to the hippocampus revealed a pattern of LE that included mild perivascular lymphocytic cuffing and scattered foci of lymphocytes in the parenchyma, predominantly in the CA4 region. Microglial nodules were rarely identified.

Diagnosis and Treatment: This is a rare disorder with few confirmed cases. However, suspected patients present with a subacute onset of and rapid progression of working memory deficits, seizures, and psychiatric symptoms suggesting involvement of the limbic system. Supporting laboratory findings include unilateral or bilateral abnormalities on T2/FLAIR brain MRI involving the medial temporal lobes with CSF pleocytosis and EEG findings of epileptic or focal slow wave activity also involving the temporal lobes. The finding of increased titers of serum and CSF AMPA antibodies with intrathecal synthesis makes the diagnosis certain. There may be associated autoimmune or additional antibodies to IAg 
and SAg, and a high likelihood of a concomitant neoplasm.

Follow-up for a mean of 72 weeks was available from 21 of 22 cases studied by Höfrberger and coworkers [164] who received first-line immunotherapy consisting of corticosteroids, IV immunoglobulins, or plasma exchange, and 5 others who received second-line biological therapies. Thirteen patients underwent oncologic treatments consisting of tumor resection, chemotherapy, and radiation therapy. At last follow-up, 10 patients has a partial favorable response and 6 patients had no response; and 5 patients died of cancer. Clinical relapse occurred in only one patient in the analysis by Höfrberger and coworkers [164] but in 5 [50\%] of patients reported by Lai and colleagues [163]. In virtually all of those patients, the clinical response to treatment was also partial, consistent with a favorable response to immunosuppression, yet eventual neurological deterioration related to a prominent cytotoxic T-cell immunity notably in the setting of cancer.

\section{Conclusion}

Autoimmune encephalitis has provided a valuable link between the research and clinical realms, and at the convergence of neuroscience and psychiatry, with many autoantibody syndromes straddling the two worlds, all for the benefit of affected patients. Future research endeavors will be oriented toward understanding basic underlying mechanisms of these conditions, such as the cause, production and distribution of specific autoantibodies in the serum and CSF, and identifying with further precision the underlying autoimmune responses so important in pathogenesis and response to treatment. Further information can be found on-line (http://www.davidsyounger.com).

\section{Acknowledgements}

The author is grateful to New York University Langone Medical Center that provides ongoing opportunities to investigate the multidisciplinary aspects of autoimmune encephalitis and its varied neuropsychiatric manifestations.

\section{Conflict of Interest}

The author denies any conflict of interest.

\section{References}

[1] Corsellis, J.A., Goldberg, G.J. and Norton, A.R. (1968) "Limbic Encephalitis" and Its Association with Carcinoma. Brain, 91, 481-496.

https://doi.org/10.1093/brain/91.3.481

[2] Brierley, J.B. (1960) Subacute Encephalitis of Later Adult Life. Mainly Affecting the Limbic Areas. Brain, 83, 357-368. https://doi.org/10.1093/brain/83.3.357

[3] Henson, R.A., Russell, D.S. and Wilkinson, M. (1954) Carcinomatous Neuropathy and Myopathy a Clinical and Pathological Study. Brain, 77, 82-121. https://doi.org/10.1093/brain/77.1.82

[4] Younger, D.S., Graber, J., Hayakawa-Yano, Y., et al. (2013) Ri/Nova Gene-Associated Paraneoplastic Subacute Motor Neuronopathy. Muscle Nerve, 47, 617-618. 
https://doi.org/10.1002/mus.23783

[5] Budde-Steffen, C., Anderson, N.E., Rosenblum, M.K., et al. (1988) An Antineuronal Autoantibody in Paraneoplastic Opsoclonus. Annals of Neurology, 23, 528-531. https://doi.org/10.1002/ana.410230518

[6] Graus, F., Rowe, G., Fueyo, J., et al. (1993) The Neuronal Nuclear Antigen Recognized by the Human Anti-Ri Autoantibody Is Expressed in Central but Not Peripheral Nervous System Neurons. Neuroscience Letters, 150, 212-214. https://doi.org/10.1016/0304-3940(93)90538-V

[7] Buckanovich, R.J., Posner, J.B. and Darnell, R.B. (1993) Nova, the Paraneoplastic Ri Antigen, Is Homologous to an RNA-Binding Protein and Is Specifically Expressed in the Developing Motor System. Neuron, 11, 657-672. https://doi.org/10.1016/0896-6273(93)90077-5

[8] Yang, Y.Y., Yin, G.L. and Darnell, R.B. (1998) The Neuronal RNA-Binding Protein Nova-2 Is Implicated as the Autoantigen Targeted in POMA Patients with Dementia. Proceedings of the National Academy of Sciences of the United States of America, 95, 13254-13259. https://doi.org/10.1073/pnas.95.22.13254

[9] Greenlee, J.E. and Brashear, H.R. (1983) Antibodies to Cerebellar Purkinje Cells in Patients with Paraneoplastic Cerebellar Degeneration and Ovarian Carcinoma. Annals of Neurology, 14, 609-613. https://doi.org/10.1002/ana.410140603

[10] Giometto, B., Marchiori, G.C., Nicolao, P., et al. (1997) Sub-Acute Cerebellar Degeneration with Anti-Yo Autoantibodies: Immunohistochemical Analysis of the Immune Reaction in the Central Nervous System. Neuropathology and Applied Neurobiology, 23, 468-474. https://doi.org/10.1111/j.1365-2990.1997.tb01323.x

[11] Graus, F., Cordon-Cardo, C. and Posner, J.B. (1985) Neuronal Antinuclear Antibody in Sensory Neuronopathy from Lung Cancer. Neurology, 35, 538-543. https://doi.org/10.1212/WNL.35.4.538

[12] Graus, F., Elkon, K.B., Cordon-Cardo, C., et al. (1986) Sensory Neuronopathy and Small Cell Lung Cancer: Antineuronal Antibody That Also Reacts with the Tumor. American Journal of Medicine, 80, 45-52. https://doi.org/10.1016/0002-9343(86)90047-1

[13] Gultekin, S.H., Rosenfeld, M.R., Voltz, R., et al. (2000) Paraneoplastic Limbic Encephalitis: Neurological Symptoms, Immunological Findings and Tumor Association in 50 Patients. Brain, 123, 1481-1494. https://doi.org/10.1093/brain/123.7.1481

[14] Luccinetti, C.F., Kimmel, D.W. and Lennon, V.A. (1998) Paraneoplastic and Oncologic Profiles of Patients Seropositive for Type 1 Antineuronal Nuclear Autoantibodies. Neurology, 50, 652-657. https://doi.org/10.1212/WNL.50.3.652

[15] Okano, H.J. and Darnell, R.B. (1997) A Hierarchy of Hu RNA Binding Proteins in Developing and Adult Neurons. Journal of Neuroscience, 17, 3024-3037.

[16] Darnell, R.B. (1996) Onconeural antigens and the paraneoplastic neurologic disorders: at the intersection of cancer, immunity and the brain. Proceedings of the National Academy of Sciences of the United States of America, 93, 4529-4536. https://doi.org/10.1073/pnas.93.10.4529

[17] Szabo, A., Dalmau, J., Manley, G., et al. (1991) HuD, a Paraneoplastic Encephalomyelitis Antigen Contains RNA-Binding Domains and Is Homologous to Elav and Sex Lethal. Cell, 67, 325-333. https://doi.org/10.1016/0092-8674(91)90184-Z

[18] Dalmau, J., Graus, F., Rosenblum, M.K., et al. (1991) Anti-Hu Associated Paraneoplastic Encephalomyelitis/Sensory Neuronopathy: A Clinical Study of $71 \mathrm{~Pa}-$ tients. Medicine, 71, 59-72. https://doi.org/10.1097/00005792-199203000-00001

[19] Darnell, R. (2007) NMDA Receptor as a Target in Paraneoplastic Encephalitis. An- 
nals of Neurology, 61, 3-4. https://doi.org/10.1002/ana.21074

[20] Darnell, R.B. and Posner, J.B. (2003) Paraneoplastic syndromes involving the nervous system. The New England Journal of Medicine, 349, 1543-1554. https://doi.org/10.1056/NEJMra023009

[21] Dalmau, J., Gultekin, S.H., Voltz, R., et al. (1999) Ma1, a Novel Neuron- and Testis-Specific Protein, Is Recognized by the Serum of Patients with Paraneoplastic Neurological Disorders. Brain, 122, 27-39. https://doi.org/10.1093/brain/122.1.27

[22] Voltz, R., Gultekin, S.H., Rosenfeld, M.R., et al. (1999) A Serological Marker of Paraneoplastic Limbic and Brain-Stem Encephalitis in Patients with Testicular Cancer. The New England Journal of Medicine, 340, 1788-1795. https://doi.org/10.1056/NEJM199906103402303

[23] Antoine, J.C., Honnorat, J., Anterion, C.T., et al. (1995) Limbic Encephalitis and Immunological Perturbations in Two Patients with Thymoma. Journal of Neurology, Neurosurgery, \& Psychiatry, 58, 706-710. https://doi.org/10.1136/jnnp.58.6.706

[24] Bernal, F., Graus, F., Pifarre, A., et al. (2002) Immunohistochemical Analysis of Anti-Hu-Associated Paraneoplastic Encephalomyelitis. Acta Neuropathologica, 103, 509-515. https://doi.org/10.1007/s00401-001-0498-0

[25] Blumenthal, D.T., Salzman, K.L., Digre, K.B., et al. (2006) Early Pathologic Findings and Long-Term Improvement in Anti-Ma2-Associated Encephalitis. Neurology, 67: 146-149. https://doi.org/10.1212/01.wnl.0000223647.83708.20

[26] Bien, C.G., Schulze-Bonhage, A., Deckert, M., et al. (2000) Limbic Encephalitis Not Associated with Neoplasm as a Cause of Temporal Lobe Epilepsy. Neurology, 55, 1823-1828. https://doi.org/10.1212/WNL.55.12.1823

[27] Mori, M., Kuwabara, S., Yoshiyama, M., et al. (2002) Successful immune treatment for non-paraneoplastic limbic encephalitis. Journal of the Neurological Sciences, 201, 85-88. https://doi.org/10.1016/S0022-510X(02)00188-0

[28] Solimena, M., Folli, F., Denis-Donini, S., et al. (1988) Autoantibodies to Glutamic Acid Decarboxylase in a Patient with Stiff-Man Syndrome, Epilepsy, and Type 1 Diabetes. The New England Journal of Medicine, 318, 1012-1020. https://doi.org/10.1056/NEJM198804213181602

[29] Panina-Bordignon, P., Lang, R., van Endert, P.M., et al. (1995) Cytotoxic T cells Specific for Glutamic Acid Decarboxylase in Autoimmune Diabetes. The Journal of Experimental Medicine, 181, 1923-1927. https://doi.org/10.1084/jem.181.5.1923

[30] Viglietta, V., Kent, S.C., Orban, T., et al. (2002) GAD65-Reactive T Cells Are Activated in Patients with Autoimmune Type 1a Diabetes. Journal of Clinical Investigation, 109, 895-903. https://doi.org/10.1172/JCI0214114

[31] Malter, M.P., Helmstaedter, C., Urbach, H., et al. (2010) Antibodies to Glutamic Acid Decarboxylase Define a Form of Limbic Encephalitis. Annals of Neurology, 67, 470-478. https://doi.org/10.1002/ana.21917

[32] Murinson, B.B. and Guarnaccia, J.B. (2008) Stiff-Person Syndrome with Amphiphysin Antibodies: Distinctive Features of a Rare Disease. Neurology, 71, 1955-1958. https://doi.org/10.1212/01.wnl.0000327342.58936.e0

[33] Vincent, A., Buckley, C., Schott, J.M., et al. (2004) Potassium Channel Antibody-Associated Encephalopathy: A Potentially Immunotherapy-Responsive Form of Limbic Encephalitis. Brain, 127, 701-712. https://doi.org/10.1093/brain/awh077

[34] Irani, S.R., Gelfand, J.M., Al-Diwani, A., et al. (2014) Cell-Surface Central Nervous System Autoantibodies: Clinical Relevance and Emerging Paradigms. Annals of Neurology, 76, 168-184. https://doi.org/10.1002/ana.24200

[35] Liquori, R., Vincent, A., Clover, L., et al. (2001) Morvan's Syndrome: Peripheral and 
Central Nervous System and Cardiac Involvement with Antibodies to Voltage-Gated Potassium Channels. Brain, 124, 2417-2426. https://doi.org/10.1093/brain/124.12.2417

[36] Buckley, C., Oger, J., Clover, L., et al. (2001) Potassium Channel Antibodies in Two Patients with Reversible Limbic Encephalitis. Annals of Neurology, 50, 73-78. https://doi.org/10.1002/ana.1097

[37] Graus, F., Saiz, A. and Dalmau, J. (2010) Antibodies and Neuronal Autoimmune Disorders of the CNS. Journal of Neurology, 257, 509-517. https://doi.org/10.1007/s00415-009-5431-9

[38] Dalmau, J., Graus, F., Villarejo, A., et al. (2004) Clinical Analysis of Anti-Ma2-Associated Antibodies. Brain, 127, 1831-1844. https://doi.org/10.1093/brain/awh203

[39] Alamowitch, S., Graus, F., Uchuya, M., et al. (1997) Limbic Encephalitis and Small Cell Lung Cancer-Clinical and Immunological Features. Brain, 120, 923-928. https://doi.org/10.1093/brain/120.6.923

[40] Honorat, J., Antoine, J.C., Derrington, E., et al. (1996) Antibodies to a Subpopulation of Glial Cells and a 66kDa Developmental Protein in Patients with Paraneoplastic Neurological Syndrome. Journal of Neurology, Neurosurgery, \& Psychiatry, 61, 270-278. https://doi.org/10.1136/jnnp.61.3.270

[41] Bien, C.G., Vincent, A., Barnett, M.H., et al. (2012) Immunopathology of Autoantibody-Associated Encephalitides: Clues for Pathogenesis. Brain, 135, 1622-1638. https://doi.org/10.1093/brain/aws082

[42] Bauer, J. and Bien, C.G. (2016) Neurpathology of Autoimmune Encephalitides. Handbook of Clinical Neurology, 133, 107-120. https://doi.org/10.1016/B978-0-444-63432-0.00007-4

[43] Hornigo, A., Lieberman, F. and Posner, J.B. (1994) Nuclear Localization of Anti-Hu Antibody Is Not Associated with In Vitro Cytotoxicity. Neurology, 55, 205-212.

[44] Tanaka, K., Ding, X. and Tanaka, M. (2004) Effects of Antineuronal Antibodies from Patients with Paraneoplastic Neurological Syndromes on Primary Cultured Neurons. Journal of the Neurological Sciences, 217, 25-30. https://doi.org/10.1016/j.jns.2003.08.006

[45] Bataller, L. and Dalmau, J. (2004) Paraneoplastic Disorders of the Central Nervous System: Update on Diagnostic Criteria and Treatment. Seminars in Neurology, 24, 461-471. https://doi.org/10.1055/s-2004-861540

[46] Dalmau, J., Gleichman, A.J., Hughes, E.G., et al. (2008) Anti-NMDA-Receptor Encephalitis: Case Series and Analysis of the Effects of Antibodies. The Lancet Neurology, 7, 1091-1098. https://doi.org/10.1016/S1474-4422(08)70224-2

[47] Turner, M.R., Irani, S.R., Leite, M.I., et al. (2011) Progressive Encephalomyelitis with Rigidity and Myclonus: Glycine and NMDA Receptor Antibodies. Neurology, 77: 439-443. https://doi.org/10.1212/WNL.0b013e318227b176

[48] Leypoldt, F., Armangue, T. and Dalmau, J. (2015) Autoimmune Encephalopathies. Annals of the New York Academy of Sciences, 1338, 94-114. https://doi.org/10.1111/nyas.12553

[49] Ances, B.M., Vitaliani, R., Taylor, R.A., et al. (2005) Treatment-Responsive Limbic Encephalitis Identified by Neuropil Antibodies: MRI and PET Correlates. Brain, 128, 1764-1777. https://doi.org/10.1093/brain/awh526

[50] Goldsmith, C.A. and Rogers, D.P. (2008) The Case for Autoimmunity in the Etiology of Schizophrenia. Pharmacotherapy, 28, 730-741.

https://doi.org/10.1592/phco.28.6.730 
[51] Nemeroff, C.B., Simon, J.S., Haggerty, J.J. Jr., et al. (1985) Antithyroid Antibodies in Depressed Patients. The American Journal of Psychiatry, 142, 840-843. https://doi.org/10.1176/ajp.142.7.840

[52] Ching, K.H., Burbelo, P.D., Carlson, P.J., et al. (2010) High Levels of Anti-GAD65 and Anti-Ro52 Autoantibodies in a Patient with Major Depressive Disorder Showing Psychomotor Disturbance. Journal of Neuroimmunology, 222, 87-89. https://doi.org/10.1016/j.jneuroim.2010.02.015

[53] Kayser, M.S. and Dalmau, J. (2011) The Emerging Link between Autoimmune Disorders and Neuropsychiatric Disease. The Journal of Neuropsychiatry and Clinical Neurosciences, 23, 90-97.

[54] McKeon, A. and Tracy, J.A. (2017) GAD65 Neurological Autoimmunity. Muscle Nerve, 56, 15-27. https://doi.org/10.1002/mus.25565

[55] Espay, A.J. and Chen, R. (2006) Rigidity and Spasms from Autoimmune Encephalomyelopathies: Stiff Person Syndrome. Muscle Nerve, 34, 677-690. https://doi.org/10.1002/mus.20653

[56] McKeon, A., Robinson, M.T., McEvoy, R.M., et al. (2012) Stiff-Man Syndrome and Variants: Clinical Course, Treatments, and Outcomes. Archives of Neurology, 69, 230-238. https://doi.org/10.1001/archneurol.2011.991

[57] Falip, M., Carreño, M., Miró, J., et al. (2012) Prevalence and Immunologic Spectrum of Temporal Lobe Epilepsy with Glutamic Acid Decarboxylase Antibodies. European Journal of Neurology, 19, 827-833. https://doi.org/10.1111/j.1468-1331.2011.03609.x

[58] Ariño, H., Höftberger, R., Gresa-Arribas, N., et al. (2015) Paraneoplastic Neurological Syndromes and Glutamic Acid Decarboxylase Antibodies. JAMA Neurology, 72, 874-881. https://doi.org/10.1001/jamaneurol.2015.0749

[59] Graus, F., Delattre, J.Y., Antoine, J.C., et al. (2004) Recommended Diagnostic Criteria for Paraneoplastic Neurological Syndromes. Journal of Neurology, Neurosurgery, \& Psychiatry, 75, 1135-1140. https://doi.org/10.1136/jnnp.2003.034447

[60] Gagnon, M.-M. and Savard, M. (2016) Limbic Encephalitis: Associated with GAD65 Antibodies: Brief Review of the Relevant Literature. Canadian Journal of the Neurological Sciences, 43, 486-493. https://doi.org/10.1017/cjn.2016.13

[61] Giometto, B., Nicolao, P., Macucci, M., et al. (1998) Temporal Lobe Epilepsy Associated with Glutamic-Acid-Decarboxylase Autoantibodies. Lancet, 352-457. https://doi.org/10.1016/S0140-6736(05)79192-3

[62] Petit-Pedrol, M., Armangue, T., Peng, X., et al. (2014) Encephalitis with Refractory Seizures, Status Epilepticus and Antibodies to the GABA $\mathrm{A}$ Receptor: A Case Series, Characterization of the Antigen, and Analysis of the Effects of Antibodies. The Lancet Neurology, 13, 276-286. https://doi.org/10.1016/S1474-4422(13)70299-0

[63] Lin, J.J., Lin, K.L., Hsia, S.H., CHEESE Study Group, et al. (2012) Antiglutamic Acid Decarboxylase Antibodies in Children with Encephalitis and Status Epilepticus. Pediatric Neurology, 47, 252-258. https://doi.org/10.1016/j.pediatrneurol.2012.06.013

[64] Finelli, P.F. (2011) Autoimmune Limbic Encephalitis with GAD Antibodies. Neurohospitalist, 1, 178-181. https://doi.org/10.1177/1941875211413135

[65] Mirabelli-Badenier, M., Morana, G., Pinto, F., et al. (2012) Anti-Glutamic Acid Decarboxylase Limbic Encephalitis without Epilepsy Evolving into Dementia with Cerebellar Ataxia. Archives of Neurology, 69, 1064-1066.

https://doi.org/10.1001/archneurol.2012.234

[66] Kanter, I.C., Huttner, H.B., Staykov, D., et al. (2008) Cyclophosphamide for Anti-GAD Antibody-Positive Refractory Status Epilepticus. Epilepsia, 49, 914-920. 
https://doi.org/10.1111/j.1528-1167.2007.01500.x

[67] Garcìa, M.E., Catrillo, S.M., Morales, I.G., et al. (2013) Acute Amnesia and Seizures in Young Female. Epileptic Disorders, 15, 55-60.

[68] Marchiori, G.C., Vaglia, A. and Vianello, M. (2001) Encephalitis Associated with Glutamic Acid Decarboxylase Autoantibodies. Neurology, 56, 814. https://doi.org/10.1212/WNL.56.6.814

[69] Matà, S., Muscas, G.C., Naldi, I., et al. (2008) Non-Paraneoplastic Limbic Encephalitis Associated with Anti-Glutamic Acid Decarboxylase Antibodies. Journal of Neuroimmunology, 199, 155-159. https://doi.org/10.1016/j.jneuroim.2008.05.015

[70] Akman, C., Patterson, M., Rubinstein, A., et al. (2009) Limbic Encephalitis Associated with Anti-GAD Antibody and Common Variable Immune Deficiency. Developmental Medicine \& Child Neurology, 51, 563-567. https://doi.org/10.1111/j.1469-8749.2008.03217.x

[71] Cikrikçili, U., Ulusoy, C., Turan, S., et al. (2013) Non-Convulsive Status Epilepticus Associated with Glutamic Acid Decarboxylase Antibody. Clinical EEG and Neuroscience, 44, 232-236. https://doi.org/10.1177/1550059412459330

[72] Olson, J.A., Olson, D.M., Sandborg, C., et al. (2002) Type 1 Diabetes Mellitus and Epilepsia Partialis Continua in a 6-Year-Old Boy with Elevated Anti-GAD65 Antibodies. Pediatrics, 109, 50. https://doi.org/10.1542/peds.109.3.e50

[73] Baglietto, M.G., Mancardi, M.M., Giannattasio, A., et al. (2009) Epilepsia Partialis Continua in Type 1 Diabetes: Evolution into Encephalopathy with Continuous Spike-Waves during Slow Sleep. Neurological Sciences, 30, 509-512. https://doi.org/10.1007/s10072-009-0122-y

[74] Blanc, F., Ruppert, E., Kleitz, C., et al. (2009) Acute Limbic Encephalitis and Glutamic Acid Decarboxylase Antibodies: A Reality? Journal of the Neurological Sciences, 287, 69-71. https://doi.org/10.1016/j.jns.2009.09.004

[75] Saiz, A., Blanco, Y., Sabater, L., et al. (2008) Spectrum of Neurological Syndromes Associated with Glutamic Acid Decarboxylase Antibodies: Diagnostic Clues for This Association. Brain, 131, 2553-2563. https://doi.org/10.1093/brain/awn183

[76] Knudsen A., Bredholt G., Storstein A., et al. (2007) Antibodies to CRMP3-4 Associated with Limbic Encephalitis and Thymoma. Clinical \& Experimental Immunology, 149, 16-22. https://doi.org/10.1111/j.1365-2249.2007.03379.x

[77] Graus, F., Saiz, A., Lai, M., et al. (2008) Neuronal Surface Antigen Antibodies in Limbic Encephalitis. Neurology, 71, 930-936. https://doi.org/10.1212/01.wnl.0000325917.48466.55

[78] Haberlandt, E., Bast, T., Ebner, A., et al. (2011) Limbic Encephalitis in Children and Adolescents. Archives of Disease in Childhood, 96, 186-191. https://doi.org/10.1136/adc.2010.183897

[79] Lopez-Sublet, M., Bihan, H., Reach, G., et al. (2012) Limbic Encephalitis and Type 1 Diabetes with Glutamic Acid Decarboxylase 65 (GAD65) Autoimmunity: Improvement with High-Dose Intravenous Immunoglobulin Therapy. Diabetes \& Metabolism, 38, 273-275. https://doi.org/10.1016/j.diabet.2012.02.005

[80] Sharma, A., Dubey, D., Sawhney, A., et al. (2012) GAD65 Positive Autoimmune Limbic Encephalitis: A Case Report and Review of Literature. Journal of Clinical Medicine Research, 4, 424-428.

[81] Korff, C.M., Parvez, P., Cisamoni, L., et al. (2011) Encephalitis Associated with Glutamic Acid Decarboxylase Autoantibodies in a Child: A Treatable Condition? Archives of Neurology, 68, 1065-1068. https://doi.org/10.1001/archneurol.2011.177

[82] Monnerat, B.Z., Velasco, T.R., Nakano, F.N., et al. (2013) Opercular Myoclonic 
Anarthric Status Epilepticus Due to Glutamic Acid Decarboxylase Antibody-Associated Encephalitis. Epileptic Disorders, 15, 342-346.

[83] Mazzi, G., De Roia, D., Cruciatti, B., et al. (2008) Plasma Exchange for Anti Gad-Associated Non Paraneoplastic Limbic Encephalitis. Transfusion and Apheresis Science, 29, 229-233. https://doi.org/10.1016/j.transci.2008.09.005

[84] Boronat, A., Sabater, L., Saiz, A., et al. (2011) GABAB Receptor Antibodies in Limbic Encephalitis and Anti-Gad-Associated Neurologic Disorders. Neurology, 76, 795-800. https://doi.org/10.1212/WNL.0b013e31820e7b8d

[85] Cianci, V., Labate, A., Lanza, P., et al. (2010) Non-Paraneoplastic Limbic Encephalitis Characterized by Mesio-Temporal Seizures and Extra-Temporal Lesions: A Case Report. Seizure, 19, 446-449. https://doi.org/10.1016/j.seizure.2010.06.002

[86] Saidha, S., Murphy, S., Ronayne, A., et al. (2010) Treatment of Anti-Glutamic Acid Decarboxylase Antibody-Associated Limbic Encephalitis with Mycophenolate Mofetil. Journal of Neurology, 257, 1035-1038. https://doi.org/10.1007/s00415-010-5476-9

[87] Markakis, I., Alexopoulos, H., Poulopoulou, C., et al. (2014) Immunotherapyresponsive Limbic Encephalitis with Antibodies to Glutamic Acid Decarboxylase. Journal of the Neurological Sciences, 343, 192-194. https://doi.org/10.1016/j.jns.2014.05.032

[88] Pandit, A.K., Ihtisham, K., Garg, A., et al. (2013) Autoimmune Encephalitis: A Potentially Reversible Cause of Status Epilepticus, Epilepsy, and Cognitive Decline. Annals of Indian Academy of Neurology, 16, 577-584. https://doi.org/10.4103/0972-2327.120476

[89] Mishra, N., Rodan, L.H., Nita, D.A., et al. (2014) Anti-Glutamic Acid Decarboxylase Antibody Associated Limbic Encephalitis in a Child: Expanding the Spectrum of Pediatric Inflammatory Brain Diseases. Journal of Child Neurology, 29, 677-683. https://doi.org/10.1177/0883073813500527

[90] Fenalti, G. and Buckle, A.M. (2010) Structural Biology of the GAD Autoantigen. Autoimmunity Reviews, 9, 148-152. https://doi.org/10.1016/j.autrev.2009.05.003

[91] Bien, C.G., Urbach, H., Schramm, J., et al. (2007) Limbic Encephalitis as a Precipitating Event in Adult-Onset Temporal Lobe Epilepsy. Neurology, 69, 1236-1244. https://doi.org/10.1212/01.wnl.0000276946.08412.ef

[92] Dalmau, J. and Bataller, L. (2007) Limbic Encephalitis: The New Cell Membrane Antigens and a Proposal of Clinical-Immunological Classification with Therapeutic Implications. Neurologia, 22, 526-537.

[93] Prüss, H., Dalmau, J., Harms, L., et al. (2010) Retrospective Analysis of NMDA Receptor Antibodies in Encephalitis of Unknown Origin. Neurology, 75, 1735-1739. https://doi.org/10.1212/WNL.0b013e3181fc2a06

[94] Thomas, L., Mailles, A., Desestret, V., et al. (2014) Autoimmune N-methyl-Daspartate Glutamate Receptor Antibodies in Patient with an Initial Diagnosis of Schizophrenia: Specific Relevance of IgG NR 1a Antibodies for Distinction from N-methyl-D-aspartate Glutamate Receptor Encephalitis. Journal of Infection, 68, 419-425. https://doi.org/10.1016/j.jinf.2013.12.001

[95] Granerod, J., Ambrose, H.E., Davies, N.W., et al. (2010) Causes of Encephalitis and Differences in Their Clinical Presentations in England: A Multicenter, Population-Based Prospective Study. The Lancet Infectious Diseases, 10, 835-844. https://doi.org/10.1016/S1473-3099(10)70222-X

[96] Izuka, T., Sakai, F., Ide, T., et al. (2008) Anti-NMDA Receptor Encephalitis in Japan: Long-Term Outcome without Tumor Removal. Neurology, 70, 504-511. https://doi.org/10.1212/01.wnl.0000278388.90370.c3 
[97] Dalmau, J., Lancaster, E., Martinez-Hernandez, E., et al. (2011) Clinical Experience and Laboratory Investigations in Patients with Anti-NMDAR Encephalitis. The Lancet Neurology, 10, 63-74. https://doi.org/10.1016/S1474-4422(10)70253-2

[98] Sansing, L.H., Tuzun, E., Ko, M.W., et al. (2007) A patient with encephalitis associated with NMDA receptor antibodies. Nature Clinical Practice Neurology, 3, 291-296. https://doi.org/10.1038/ncpneuro0493

[99] Armangue, T., Moris, G., Cantarin-Extremera, V., et al. (2015) Autoimmune Post-Herpes Simplex Encephalitis of Adults and Teenagers. Neurology, 85, 1736-1743. https://doi.org/10.1212/WNL.0000000000002125

[100] Irani, S.R., Bera, K., Waters, P., et al. (2010) N-methyl-D-aspartate Antibody Encephalitis: Temporal Progression of Clinical and Paraclinical Observations in a Predominantly Nonparaneoplastic Disorder of Both Sexes. Brain, 133, 1655-1667. https://doi.org/10.1093/brain/awq113

[101] Titulaer, M.J., McCracken, L., Gabilondo, I., et al. (2013) Treatment and Prognostic Factor for Long-Term Outcome in a Patient with $N$-methyl-D-aspartate (NMDA) Receptor Encephalitis: A Cohort Study. The Lancet Neurology, 12, 157-165. https://doi.org/10.1016/S1474-4422(12)70310-1

[102] Martinez-Hernandez, E., Horvath, J., Shiloh-Malawsky, Y., et al. (2011) Analysis of Complement and Plasma Cells in the Brain of Patients with Anti-NMDAR Encephalitis. Neurology, 77, 589-593. https://doi.org/10.1212/WNL.0b013e318228c136

[103] Kelley, B.P., Patel, S.C., Marin, H.L., et al. (2017) Autoimmune Encephalitis: Pathophysiology and Imaging Review of an Overlooked Diagnosis. American Journal of Neuroradiology, 38, 1070-1078. https://doi.org/10.3174/ajnr.A5086

[104] Dalmau, J. and Rosenfeld, M.R. (2008) Paraneoplastic Syndromes of the CNS. The Lancet Neurology, 7, 327-340. https://doi.org/10.1016/S1474-4422(08)70060-7

[105] Dalmau, J., Tuzun, E., Hai-Yan, W., et al. (2007) Paraneoplastic Anti-N-methyl-D-aspartate Receptor Encephalitis Associated with Ovarian Teratoma. Annals of Neurology, 61, 25-36. https://doi.org/10.1002/ana.21050

[106] Stein-Wexler, R., Wootton-Gorges, S.L., Greco, C.M., et al. (2005) Paraneoplastic Limbic Encephalitis in a Teenage Girl with an Immature Ovarian Tetratoma. Pediatric Radiology, 35, 694-697. https://doi.org/10.1007/s00247-005-1402-1

[107] Tüzün, E., Zhou, L., Baehring, J.M., et al. (2009) Evidence for Antibody-Mediated Pathogenesis in Anti-NMDAR Encephalitis Associated with Ovarian Teratoma. Acta Neuropathologica, 118, 737-743. https://doi.org/10.1007/s00401-009-0582-4

[108] Camdessanche, J.P., Streichenberger, N., Cavillon, G., et al. (2011) Brain Immunohistopathological Study in a Patient with Anti-NMDAR Encephalitis. European Journal of Neurology, 18, 929-931. https://doi.org/10.1111/j.1468-1331.2010.03180.x

[109] Hughes, E.G., Peng, X., Gleichman, A.J., et al. (2010) Celllular and Synaptic Mechanisms of Anti-NMDA Receptor Encephalitis. Journal of Neuroscience, 30, 5866-5875. https://doi.org/10.1523/JNEUROSCI.0167-10.2010

[110] Graus, F., Titulaer, M.J., Balu, R., et al. (2016) A Clinical Approach to Diagnosis of Autoimmune Encephalitis. The Lancet Neurologyogy, 15, 391-404. https://doi.org/10.1016/S1474-4422(15)00401-9

[111] Schott, J.M., Harkness, K., Barnes, J., et al. (2003) Amnesia, Cerebral Atrophy, and Autoimmunity. Lancet, 361, 1266. https://doi.org/10.1016/S0140-6736(03)12983-2

[112] Thieben, M.J., Lennon, V.A., Boeve, B.F., et al. (2004) Potentially Reversible Autoimmune Limbic Encephalitis with Neuronal Potassium Channel Antibody. Neurology, 62, 1177-1182. https://doi.org/10.1212/01.WNL.0000122648.19196.02 
[113] Parthasarathi, U.D., Harrower, T., Tempest, M., et al. (2006) Psychiatric Presentation of Voltage-Gated Potassium Channel Antibody-Associated Encephalopathy. Case Report. The British Journal of Psychiatry, 189, 182-183. https://doi.org/10.1192/bjp.bp.105.012864

[114] Lai, M., Huijbers, M.G., Lancaster, E., et al. (2010) Investigation of LGI1 as the Antigen in Limbic Encephalitis Previously Attributed to Potassium Channels: A Case Series. The Lancet Neurology, 9, 776-785. https://doi.org/10.1016/S1474-4422(10)70137-X

[115] Irani, S.R., Alexander, S., Waters, P., et al. (2010) Antibodies to Kv1 Potassium Channel-Complex Proteins Leucine-Rich, Glioma Inactivated 1 Protein and Contactin-Associated Protein-2 in Limbic Encephalitis, Morvan's Syndrome and Acquired Neuromyotonia. Brain, 133, 2734-2748.

https://doi.org/10.1093/brain/awq213

[116] Hart, I.K., Waters, C., Vincent, A., et al. (1997) Autoantibodies Detected to Expressed K+ Channels Are Implicated in Neuromyotonia. Annals of Neurology, 41, 238-24. https://doi.org/10.1002/ana.410410215

[117] Kleopa, K.A., Elman, L.B., Lang, B., et al. (2006) Neuromyotonia and Limbic Encephalitis Sera Target Mature Shaker-Type K+ Channels: Subunit Specificity Correlates with Clinical Manifestations. Brain, 129, 1570-1584. https://doi.org/10.1093/brain/awl084

[118] Lancaster, E., Huijbers, M.G., Bar, V. et al. (2011) Investigations of Caspr2, an Autoantigen of Encephalitis and Neuromyotonia. Annals of Neurology, 69, 303-311. https://doi.org/10.1002/ana.22297

[119] Boronat, A., Sepúlveda, M. and Llufriu, S. (2012) Analysis of Antibodies to Surface Epitopes of Contactin-2 in Multiple Sclerosis. Journal of Neuroimmunology, 244, 103-106. https://doi.org/10.1016/j.jneuroim.2011.12.023

[120] Klein, C.J., Lennon, V.A., Aston, P.A., et al. (2013) Insights from LGI1 and CASPR2 Potassium Channel Complex Autoantibody Subtyping. JAMA Neurology, 70, 229-234. https://doi.org/10.1001/jamaneurol.2013.592

[121] Granerod, J., Cousens, S., Davies, N.W., et al. (2013) New Estimates of Incidence of Encephalitis in England. Emerging Infectious Diseases, 19, 1455-1462. https://doi.org/10.3201/eid1909.130064

[122] Lin, J.J., Lin, K.L., Wang, H.S., et al. (2013) VGKG Complex Antibodies in Pediatric Severe Acute Encephalitis: A Study and Literature Review. Brain \& Development, 35, 630-635. https://doi.org/10.1016/j.braindev.2012.09.012

[123] Irani, S.R. and Vincent, A. (2016) Voltage-Gated Potassium Channel-Complex Autoimmunity and Associated Clinical Syndromes. Handbook of Clinical Neurology, 133, 185-217. https://doi.org/10.1016/B978-0-444-63432-0.00011-6

[124] Flanagan, E.P., McKeon, A., Lennon, V.A., et al. (2010) Autoimmune Dementia: Clinical Course and Predictors of Immunotherapy Response. Mayo Clinic Proceedings, 85, 881-897. https://doi.org/10.4065/mcp.2010.0326

[125] Bettcher, B.M., Gelfand, J.M., Irani, S.R., et al. (2014) More Than Memory Impairment in Voltage-Gated Potassium Channel Complex Encephalopathy. European Journal of Neurology, 21: 1301-1310. https://doi.org/10.1111/ene.12482

[126] Kalachikov, S., Evgrafov, O., Ross, B., et al. (2002) Mutations in LGI1 Cause Autosomal-Dominant Partial Epilepsy with Auditory Features. Nature Genetics, 30, 335-341. https://doi.org/10.1038/ng832

[127] Ohkawa, T., Fukata, Y., Yamasaki, M., et al. (2013) Autoantibodies to Epilepsy-Related LGI1 in Limbic Encephalitis Neutralize LGI1-ADAM22 Interaction and 
Reduce Synaptic AMPA Receptor. The Journal of Neuroscience, 33, 18161-18174. https://doi.org/10.1523/JNEUROSCI.3506-13.2013

[128] Fukata, Y., Lovero, K.L., Iwanaga, T., et al. (2010) Disruption of LGI1-Linked Synaptic Complex Causes Synaptic Transmission and Epilepsy. Proceedings of the National Academy of Sciences of the United States of America, 107: 3799-3804. https://doi.org/10.1073/pnas.0914537107

[129] Younger, D.S. (2017) Limbic Encephalitis Associated with Voltage-Gated Potassium Channel-Complex Antibodies: Patient Report and Literature Review. World Journal of Neuroscience, 7, 19-31. https://doi.org/10.4236/wjns.2017.71002

[130] Cornelius, J.R., Pittock, S.J., McKeon, A., et al. (2011) Sleep Manifestations of Voltage-Gated Potassium Channel Complex Autoimmunity. Archives of Neurology, 68, 733-738. https://doi.org/10.1001/archneurol.2011.106

[131] Geschwind, M.D., Tan, K.M., Lennon, V.A., et al. (2008) Voltage-Gated Potassium Channel Autoimmunity Mimicking Creutzfeldt-Jakob Disease. Archives of Neurology, 65, 1341-1346. https://doi.org/10.1001/archneur.65.10.1341

[132] Klein, C.J., Lennon, V.A., Aston, P.A., et al. (2012) Chronic Pain as a Manifestation of Potassium Channel-Complex Autoimmunity. Neurology, 79, 1136-1144. https://doi.org/10.1212/WNL.0b013e3182698cab

[133] Bennett, D.L.H. and Vincent, A. (2012) Autoimmune Pain. Neurology, 79, 1080-1081. https://doi.org/10.1212/WNL.0b013e3182698dc3

[134] Brouwer, B.A., Merkies, I.S., Gerrits, M.M., et al. (2014) Painful Neuropathies: The Emerging Role of Sodium Channelopathies. Journal of the Peripheral Nervous System, 19, 53-65. https://doi.org/10.1111/jns5.12071

[135] Lahoria, R., Pittock, S.J., Gadoth, A., et al. (2017) Clinical-Pathologic Correlations in VGKC-Subtyped Autoimmune Painful Polyneuropathy. Muscle Nerve, 55, 520-525. https://doi.org/10.1002/mus.25371

[136] Lancaster, E. and Dalmau, J. (2012) Neuronal Autoantigens-Pathogenesis, Associated Disorders and Antibody Testing. Nature Reviews Neurology, 8, 380-390. https://doi.org/10.1038/nrneurol.2012.99

[137] Chatzopoulou, E., Miguez, A., Savvaki, M., et al. (2008) Structural Requirement of TAG-1 for Retinal Ganglion Cell Axons and Myelin in the Mouse Optic Nerve. Journal of Neuroscience, 28: 7624-7636. https://doi.org/10.1523/JNEUROSCI.1103-08.2008

[138] Lalic, T., Pettingill, P., Vincent, A., et al. (2011) Human Limbic Encephalitis Serum Enhances Hippocampal Mossy Fiber-CA3 Pyramidal Cell Synaptic Transmission. Epilepsia, 52, 121-131. https://doi.org/10.1111/j.1528-1167.2010.02756.x

[139] Verkerk, A.J., Mathews, C.A., Joosse, M., et al. (2003) CNTNAP2 is Disrupted in a Family with Gilles de la Tourette Syndrome and Obsessive Compulsive Disorder. Genomics, 82, 1-9. https://doi.org/10.1016/S0888-7543(03)00097-1

[140] Strauss, K.A., Puffenberger, E.G., Huentelman, M.J., et al. (2006) Recessive Symptomatic Focal Epilepsy and Mutant Contactin-Associated Protein-Like 2. The New England Journal of Medicine, 354: 1370-1377. https://doi.org/10.1056/NEJMoa052773

[141] Gregor, A., Albrecht, B., Bader, I., et al. (2011) Expanding the Clinical Spectrum Associated with Defects in CNTNAP2 and NRXN1. BMC Medical Genetics, 12, 106. https://doi.org/10.1186/1471-2350-12-106

[142] Peñagarikano, O., Abrahams, B.S. and Herman, E.I. (2011) CNTNAP2 Leads to Epilepsy, Neuronal Migration Abnormalities, and Core Autism-Related Deficits. Cell, 147, 235-246. https://doi.org/10.1016/j.cell.2011.08.040 
[143] Whalley, H.C., O'Connell, G. and Sussmann, J.E. (2011) Genetic Variation in CNTNAP2 Alters Brain Function during Linguistic Processing in Healthy Individuals. American Journal of Medical Genetics Part B: Neuropsychiatric Genetics, 156B: 941-948. https://doi.org/10.1002/ajmg.b.31241

[144] Apiwattanakul, M., McKeon, A., Pittock, S.J., et al. (2010) Eliminating False-Positive Results in Serum Tests for Neuromuscular Autoimmunity. Muscle Nerve, 41, 702-704. https://doi.org/10.1002/mus.21653

[145] Van Sonderen, A., Schreurs, M.W., de Bruijn, M.A., et al. (2016) The Relevance of VGKC Positivity in the Absence of LGI1 and Caspr2 Antibodies. Neurology, 86: 1692-16993. https://doi.org/10.1212/WNL.0000000000002637

[146] Graus, F. and Gorman, M.P. (2016) Voltage-Gated Potassium Channel Antibodies. Neurology, 86, 1657-1658. https://doi.org/10.1212/WNL.0000000000002644

[147] Irani, S.R., Pettingill, P., Kleopa, K.A., et al. (2012) Morvan Syndrome: Clinical and Serological Observations in 29 Cases. Annals of Neurology, 72, 241-255. https://doi.org/10.1002/ana.23577

[148] Paterson, R.W., Zandi, M.S., Armstrong, R., et al. (2014) Clinical Relevance of Positive Voltage-Gated Potassium Channel (VGKC)-Complex Antibodies: Experience from a Tertiary Referral Centre. Journal of Neurology, Neurosurgery, \& Psychiatry, 85, 625-630. https://doi.org/10.1136/jnnp-2013-305218

[149] Gast, H., Schindler, K., Z’Graggen, W.J., et al. (2010) Improvement of Non-Paraneoplastic Voltage-Gated Potassium Channel Antibody-Associated Limbic Encephalitis without Immunosuppressive Therapy. Epilepsy \& Behavior, 17, 555-557. https://doi.org/10.1016/j.yebeh.2010.01.017

[150] Day, B.K., Eisenman, L., Black, J., et al. (2015) A Case Study of Voltage-Gated Potassium Channel Antibody-Related Limbic Encephalitis with PET/MRI Findings. Epilepsy \& Behavior Case Reports, 4, 23-26. https://doi.org/10.1016/j.ebcr.2015.02.002

[151] Baumbartner, A., Rauer, S., Mader, I., et al. (2013) Cerebral FDG-PET and MRI Findings in Autoimmune Limbic Encephalitis: Correlation with Autoantibody Types. Journal of Neurology, 260, 2744-2753. https://doi.org/10.1007/s00415-013-7048-2

[152] Jarius, S., Hoffman, L., Clover, L., et al. (2008) CSF Findings in Patients with Voltage Gated Potassium Channel Antibody Associated Limbic Encephalitis. Journal of the Neurological Sciences, 268, 74-77. https://doi.org/10.1016/j.jns.2007.11.004

[153] Rhodes, K.J., Monagham, M.M., Barrezueta, N.X., et al. (1996) Voltage-Gated K+ Channel Beta Subunits: Expression and Distribution of KVBETA1 and KVBETA2 in Adult Rat Brain. Journal of Neuroscience, 16, 4846-4860.

[154] Monaghan, M.M., Trimmer, J.S. and, Rhodes, K.J. (2001) Experimental Localization of Kv1 Family Voltage-Gated K+ Channel Alpha and Beta Subunits in Rat Hippocampal Formation. Journal of Neuroscience, 21, 5973-5983.

[155] Chan, A.C., and Wilder-Smith, E.P. (2016) Small Fiber Neuropathy: Getting Bigger! Muscle Nerve, 53, 671-682. https://doi.org/10.1002/mus.25082

[156] Lacomis, D. (2002) Small-Fiber Neuropathy. Muscle Nerve, 26, 173-188. https://doi.org/10.1002/mus.10181

[157] Low, P.A., Tomalia, V.A. and Park, K.J. (2013) Autonomic Function Tests: Some Clinical Applications. Journal of Clinical Neurology, 9, 1-8.

https://doi.org/10.3988/jcn.2013.9.1.1

[158] Dunstan, E.J. and Winer, J.B. (2006) Autoimmune Limbic Encephalitis Causing Fits, Rapidly Progressive Confusion and Hyponatremia. Age and Aging, 35, 536-537. 
https://doi.org/10.1093/ageing/afl045

[159] Park, D.C., Murman, D.L., Perry, K.D., et al. (2007) An Autopsy Case of Limbic Encephalitis with Voltage-Gated Potassium Channel Antibodies. European Journal of Neurology, 14, e5-e6. https://doi.org/10.1111/j.1468-1331.2007.01924.x

[160] Khan, N.L., Jeffree, M.A., Good, C., et al. (2009) Histopathology of VGKC Antibody-Associated Limbic Encephalitis. Neurology, 72, 1703-1705. https://doi.org/10.1212/WNL.0b013e3181a55eb3

[161] Bataller, L., Kleopa, K.A., Wu, G.F., et al. (2007) Autoimmune Limbic Encephalitis in 39 Patients: Immunophenotypes and Outcomes. Journal of Neurology, Neurosurgery, \& Psychiatry, 78, 381-385. https://doi.org/10.1136/jnnp.2006.100644

[162] Morante-Redolat, J.M., Gorostidi-Pagola, A., Piquer-Sirerol, S., et al. (2002) Mutations in the LGI1/Epitemprin Gene on 10q24 Cause Autosomal Dominant Lateral Temporal Epilepsy. Human Molecular Genetics, 11, 1119-1128. https://doi.org/10.1093/hmg/11.9.1119

[163] Lai, M., Hughes, E.G., Peng, X., et al. (2009) AMPA Receptor Antibodies in Limbic Encephalitis Alter Synaptic Receptor Location. Annals of Neurology, 65, 424-434. https://doi.org/10.1002/ana.21589

[164] Höfrberger, R., van Sonderen, A., Leypoldt, F., et al. (2015) Encephalitis and AMPA Receptor Antibodies. Novel Findings in a Case Series of 22 Patients. Neurology, 84, 2403-2412. https://doi.org/10.1212/WNL.0000000000001682

[165] Sprengel, R. (2006) Role of AMPA Receptors in Synaptic Plasticity. Cell and Tissue Research, 326, 447-455. https://doi.org/10.1007/s00441-006-0275-4

[166] Palmer, C.L., Cotton, L. and Henley, J.M. (2005) The Molecular Pharmacology and Cell Biology of $\alpha$-Amino-3-hydroxy-5-methyl-4-isoxazolepropionic Acid Receptors. Pharmacological Reviews, 57, 253-277. https://doi.org/10.1124/pr.57.2.7

[167] Slipczuk, L., Bekinschtein, P., Katche, C., et al. (2009) BDNF Activates mTOR to Regulate GluR1 Expression Required for Memory Formation. PLoS One, 4, e6007. https://doi.org/10.1371/journal.pone.0006007

Submit or recommend next manuscript to SCIRP and we will provide best service for you:

Accepting pre-submission inquiries through Email, Facebook, LinkedIn, Twitter, etc. A wide selection of journals (inclusive of 9 subjects, more than 200 journals)

Providing 24-hour high-quality service

User-friendly online submission system

Fair and swift peer-review system

Efficient typesetting and proofreading procedure

Display of the result of downloads and visits, as well as the number of cited articles

Maximum dissemination of your research work

Submit your manuscript at: http://papersubmission.scirp.org/

Or contactwjns@scirp.org 